\title{
The Thorny Issue of African Porcupines: a New Mandible of Hystrix makapanensis from Olduvai Gorge (Tanzania) and Rediagnosis of the Species
}

\author{
Beatrice Azzarà ${ }^{1} \cdot$ Marco Cherin ${ }^{1}$ (D) Justin Adams ${ }^{2,3,4}$. Giovanni Boschian ${ }^{4,5} \cdot$ Marco Crotti $^{6}$. Christiane Denys ${ }^{7}$. \\ Lorenzo Fressoia ${ }^{1}$. Jackson S. Kimambo ${ }^{1,8}$. Amandus Kwekason ${ }^{9}$. Dawid A. Iurino ${ }^{10}$. Giorgio Manzi ${ }^{11}$. \\ Fidelis T. Masao ${ }^{12} \cdot$ Sahleselasie Melaku $^{13,14} \cdot$ Sofia Menconero ${ }^{15} \cdot$ Emiliano Mori $^{16} \cdot$ Bernhard Zipfel $^{8}$
}

Accepted: 4 November 2021 / Published online: 21 January 2022

(c) The Author(s), under exclusive licence to Springer Science+Business Media, LLC, part of Springer Nature 2021

\begin{abstract}
Several porcupine taxa are reported from the middle Miocene to the early Holocene in the Old World. Among these, five species of the subfamily Hystricinae occurred in Africa approximately in the last 6 Ma: the extinct Hystrix makapanensis, Hystrix leakeyi, and Xenohystrix crassidens and the still living Hystrix africaeaustralis and Hystrix cristata. The large-sized H. makapanensis is reported from numerous sites in East and South Africa between the early Pliocene and Early Pleistocene. In this paper, we describe a new mandible of H. makapanensis from the world-renowned Tanzanian paleontological and archeological site of Olduvai Gorge (HWK West; lowermost Bed II; ca. 1.8-1.7 Ma). The discovery of the new mandible triggered a comprehensive review of the entire African record of H. makapanensis. In particular, we describe or re-analyze the samples from South Africa (Makapansgat Limeworks, Gondolin, Kromdraai, Swartkrans, and Sterkfontein), Tanzania (Olduvai and Laetoli), Ethiopia (Omo Shungura and Hadar), and Kenya (Chemeron), enriching the quantity of specimens confidently referable to this species and above all improving the information on its craniodental anatomy. On this basis, we: (1) propose an emended diagnosis of H. makapanensis; (2) point out the morphological and biometric differences between H. makapanensis and other African Hystricinae (also in terms of body mass); and (3) broaden the knowledge on the geographical and chronological distribution of this extinct species.
\end{abstract}

Keywords Africa $\cdot$ Hystricidae $\cdot$ Hystricinae $\cdot$ Paleontology $\cdot$ Tanzania

\section{Introduction}

Old World porcupines (Hystricidae) are large terrestrial rodents with bodies covered by sharply pointed quills that cover their sides, back, and tail. Based on their current distribution and molecular analyses, it is generally accepted that they originated and initially diversified in southern Asia (van Weers 2005; Rovie-Ryan et al. 2017).

The family includes three genera, Trichys and Atherurus (subfamily Atherurinae) and Hystrix (subfamily Hystricinae; Happold 2013). Hystrix is the most diverse genus and is composed of eight morphologically similar extant species divided into three subgenera, Thecurus, Acanthion,

Marco Cherin

marco.cherin@unipg.it

Extended author information available on the last page of the article and Hystrix (Corbet and Jones 1965), with the first one sometimes considered as a separate genus (e.g., Masini and Rook 1993; Rovie-Ryan et al. 2017). The genus Hystrix has a wide geographical distribution in middle latitude temperate and semiarid environments of Eurasia and Africa, both on islands and mainland (Amori et al. 2008; Sen and Purabrishemi 2010).

Only two species of Hystrix can be found outside Asia, both referred to the subgenus $H$. (Hystrix): the crested porcupine Hystrix cristata and the Cape porcupine Hystrix africaeaustralis. The first occurs today in north-western, central, and eastern Africa and in Italy (where it was introduced in the VI Century AD; Trucchi and Sbordoni 2009; Trucchi et al. 2016). Hystrix africaeaustralis can be found in a wide range of environments in sub-equatorial Africa (Barthelmess 2006; Happold 2013). These two taxa are very similar in morphology but their ranges are almost completely separate, with the exception of an area between Tanzania, Uganda, 
and Kenya where they co-occur. In this area, the two species seem to prefer different habitats, i.e., $H$. cristata in drier acacia-woodlands and $H$. africaeaustralis in miombo woodlands (Kingdon 2015; Mori et al. 2019).

\section{African Fossil Porcupines}

The fossil record of hystricids in Africa is relatively scanty and is rooted in the Miocene. The two extant genera Atherurus and Hystrix and the extinct large-sized Xenohystrix are reported (Winkler et al. 2010). The first occurrence of the family is represented by Atherurus remains from Sheikh Abdallah (Egypt; ca. 11-10 Ma; Pickford et al. 2008) and Hystrix is found at Carriere Marceau (Algeria; ca. 10-9 Ma). Other fossils of this genus are reported from the late Miocene of Lemudong'o (Kenya; ca. 6 Ma; Hlusko 2007) and Middle Awash (Ethiopia, ca. 5.7 Ma; Wesselman et al. 2009) and from the Pliocene of Aramis (Ethiopia; ca. 4.4 Ma; Wesselman et al. 2009).

The genus Xenohystrix is represented in the fossil record by a single species -Xenohystrix crassidens- in several eastern and southern African late Miocene and Pliocene localities (Greenwood 1955; Haile-Selassie et al. 2004). In the 1950s a series of publications began detailing the rich faunal assemblage from the early Pliocene of Makapansgat (South Africa; ca. 3.03-2.58 Ma; Herries et al. 2013), a fossil locality near the town of Mokopane (Toerien 1952; Greenwood 1955, 1958; Ewer 1956, 1958; Wells and Cooke 1956; Hooijer 1958). The assemblage includes an extremely large-sized hystricid which Greenwood (1955) proposed to include in the novel genus and species $X$. crassidens, based on analysis of maxillary (ESI M1004, ESI M1005, ESI M1006) and mandibular (ESI M1007) remains from Member 3 deposits. The original generic diagnosis emphasized the rooting of the maxillary molars and strong curvature of the maxillary and mandibular diastemata, with the species diagnosis focused on the large size of the dentition relative to other known hystricids (Greenwood 1955). The generic diagnosis was amended by Maguire (1976) to include rooting of the mandibular molars and the shortened diastemata in addition to the curvature; and removal of the originally noted subequal dimensions of the dentition as a diagnostic criterion for Xenohystrix (as this occurs across dental wear stages of hystricids). The comparative description of $X$. crassidens specimens, alongside illustrated reconstructions of the species, represents the last formal analysis or assessment of the species beyond listing or brief mention in subsequent papers (de Graaff 1960; Denys 1987; Reed 1996). The limited attention paid to $X$. crassidens may in part reflect the paucity of the record of the species, as to date, in South Africa. The absence of the taxon in the Makapansgat members 4 and 5 faunal assemblages (per
Reed 1996; contra suggestions by Maguire 1976 that two $X$. crassidens specimens are derived from Member 4), or any subsequent South African deposits, may reflect an Early Pleistocene extinction of the genus and species in the region. However, both the geographic isolation of Makapansgat and the ca. $500 \mathrm{ka}$ hiatus in the South African fossil record between Makapansgat Member 3 and the later Pleistocene Blaubank Valley localities, make it difficult to establish a confident last-appearance date for the species in the region. As for East Africa, the earliest records of $X$. crassidens are from the late Miocene of Lemudong'o (Hlusko 2007) and Adu-Asa, Adu-Dora, and lower Sagantole Formations in Middle Awash (ca. 5.8-5.2 Ma; HaileSelassie et al. 2004; Wesselman et al. 2009). The species also occurs in the late Pliocene of Laetoli (Tanzania), Hadar and Omo (Ethiopia; Denys 1987, 2011; Winkler 2003). Therefore, in light of the absence from Quaternary deposits, Sabatier (1978) and Denys (2011) confirmed a probable extinction of $X$. crassidens close to the PlioPleistocene transition.

Regarding the genus Hystrix, the earliest records are all fragmentary and generically referred to Hystrix sp. These include the material from Toros-Menalla (Chad; ca. 7-6 Ma; Vignaud et al. 2002), Marceau (Algeria; uncertain late Miocene age; Arambourg 1959), Lothagam (Kenya; ca. 7.44 Ma; Winkler 2003), Lemudong'o (Hlusko 2007), Adu-Asa Formation (Haile-Selassie et al. 2004; Wesselman et al. 2009), and Uraha (Malawi; ca. 2.5-2.3 Ma; Denys et al. 2011). Besides these remains of uncertain attribution, the African Hystrix record is attributed to four species, the extinct Hystrix makapanensis and Hystrix leakeyi and the still living $H$. africaeaustralis and $H$. cristata.

Hystrix makapanensis was larger and more hypsodont than extant African porcupines (Denys 1987) and occurred in East and South Africa during the late Pliocene and Early Pleistocene. Hystrix sp. from the Middle Awash is possibly related to this species (Denys 2011). Hystrix makapanensis was established based on an incomplete mandible (ESI M1002) from Makapansgat Member 3 (Greenwood 1955), from where additional material has been later described (Maguire 1976; Reed 1996). To date, the only other South African site in which the species is certainly recorded is Gondolin (1.95- 1.78 Ma; Herries et al. 2006; Adams 2012a; Herries and Adams, 2013). Although $H$. makapanensis is the only hystricid from the ca. 1.8 Ma Gondolin GD 2 deposits (Adams and Conroy 2005; Adams 2012a) and the dominant hystricid from the locality overall (Adams 2018), this contrasts with the case at the well-sampled Makapansgat locality where a smaller sample exists for $H$. makapanensis from members 3-4 (NISP: 10; MNI: 5) than for $H$. africaeaustralis (NISP: 27, MNI: 5) or X. crassidens (NISP: 44, MNI: 8; Reed 1996). The species was also reported -with varying 
degrees of confidence- from Kromdraai, Sterkfontein, and Swartkrans (South Africa; Maguire 1976), Omo Shungura (Ethiopia), Laetoli and Olduvai Gorge (Tanzania; Sabatier 1978; Denys 1987, 2011).

Hystrix leakeyi is a small-sized hystricid reported only from the late Pliocene of the Upper Laetolil Beds and Hadar (Denys 2011). The specimens from Laetoli were originally described by Sabatier (1978) as H. cristata (Denys 1987). A small, very worn isolated molar from Lemudong'o with a H. leakeyi-like brachydont appearance and a molar from Kanapoi (Kenya) attributed to Hystrix sp. by Hlusko (2007) and Manthi (2006), respectively, may refer to H. leakeyi (Denys 2011).

Fossils of H. africaeaustralis are ubiquitous across the South African terminal Pliocene and Pleistocene fossil record, with reported presence in both the historical and more recently described faunal assemblages. The species is present alongside both $X$. crassidens and H. makapanensis in the late Pliocene Makapansgat Member 3 deposits (Greenwood 1955; Reed 1996) and it occurs with varying frequency within the ca. 2.0 Ma and younger deposits across the Blaubank and regional dolomitic deposits, including: Sterkfontein members 4-6, Swartkrans members 1-3, Kromdraai A and B, the Bolt's Farm Complex, Gladysvale (both External Deposits and in situ deposits), Plovers Lake, Drimolen Main Quarry, Gondolin GD A, and Haasgat HGD (Brain 1981; Pickering 1999; Lacruz et al. 2002; de Ruiter et al. 2008; Adams 2012a, 2012b, 2018; Edwards et al. 2019). As noted above, H. africaeaustralis represents the only currently confirmed hystricid occurring in these deposits other than at Gondolin and Makapansgat. However, further analyses -some of which are proposed in this paper- of isolated specimens from some of these deposits may reshape the formal attribution and composition of these assemblages. The enamel pattern of the teeth from Makapansgat is very similar to that of the living form (Greenwood 1955).

Similarly, the fossil record of $\mathrm{H}$. cristata in East Africa seems to roughly trace its current distribution and is rooted in the late Pliocene. Some Pliocene cheek teeth from the Omo deposits in Ethiopia show no significant differences with those of the extant crested porcupine, suggesting that this species has been morphologically stable for at least the last $3 \mathrm{Ma}$, with little increase in size of third molars and higher hypsodonty as the only modifications (Sabatier 1978).

In this paper, we focus our attention on the poorlyknown $H$. makapanensis. Starting from the description of a new mandible from Olduvai Gorge in Tanzania, we review the whole record of the species, emend its diagnosis, expand its geographic range, and better constrain its chronological distribution.

\section{Material and Methods}

The fossil specimen (LCOG THOR15\#81) analyzed in this work was collected in September 2015 during field activities of the Tanzania Human Origins Research (THOR) project, aimed at studying poorly-known geological, paleontological, and archaeological contexts in Olduvai Gorge (Cherin et al. 2016; Azzarà et al. 2021). LCOG THOR15\#81 is currently stored at the Leakey Camp, Olduvai Gorge. The fossil was originally covered by hard carbonate concretions (Online Resource 1), which were removed manually with a precision vibrating cutter powered by an air compressor.

The anatomical nomenclature of porcupine teeth varies in the literature. Here (Fig. 1) we follow the terminology by Sen (2001) as modified by Lopatin et al. (2003), but some alternative terms that can be found in the literature are also indicated in Online Resource 2.

In addition to the new specimen from Olduvai, we personally analyzed/reviewed the porcupine material from the following African sites (each sample's repository is indicated by the abbreviation in brackets, which is explained at the end of the section): South Africa-Makapansgat (ESI), Gondolin (DNMNH), Kromdraai (DNMNH), Swartkrans (DNMNH), Sterkfontein (DNMNH); Tanzania-Olduvai Gorge (ISEM, NHM), Laetoli (NMT); Kenya-Chemeron Formation (NMK); Ethiopia-Omo Shungura (ISEM, NME), Hadar (NME). Additional unpublished specimens from Olduvai belonging to the historical Louis Leakey collections were described based on high-resolution photographs kindly provided by the NHM.

Comparative morphological and biometric data in addition to those collected by ourselves, were taken from the following papers: Greenwood (1955), Collings et al. (1976), Maguire (1976), Sabatier (1978), Denys (1987, 2011), Barthelmess (2006), Denys et al. (2011), Adams (2012a, 2012b).

Measurements were taken with a digital caliper to the nearest $0.01 \mathrm{~mm}$. Length and width of teeth correspond to the maximum values along the mesiodistal and labiolingual axes of teeth. Additional morphological information on the new specimen LCOG THOR15\#81 was collected by means of a high-resolution 3D model with the software CloudCompare. The 3D model was built using the photogrammetric technique with Agisoft Photoscan software. Several photo sets were needed for a total of 197 photographs. The highresolution 3D model, which has more than 5 million polygons, was scaled using two scale bars. The reprojection error for the control points is $0.1 \mathrm{~mm}$. The editing of the Online Resource 1 was made using ZBrush 4R6.

Millien and Bovy (2010) published a series of prediction equations based on regressions of body mass by 
Fig. 1 Anatomical nomenclature used in this paper. a-b Right hemimandible in labial (a) and occlusal (b) views. Nomenclature from Álvarez and Arnal (2015). c-d Left P4 (c) and p4 (d) in occlusal view. Redrawn from Lopatin et al. (2003). Main cusps/cuspids are in blue, lophs/lophids in italics (green arrows). ed, entoconid; hd, hypoconid; hy, hypocone; md, metaconid; me, metacone; pa, paracone; pd, protoconid; ps, parastyle; pr, protocone. See Online Resource 2 for details
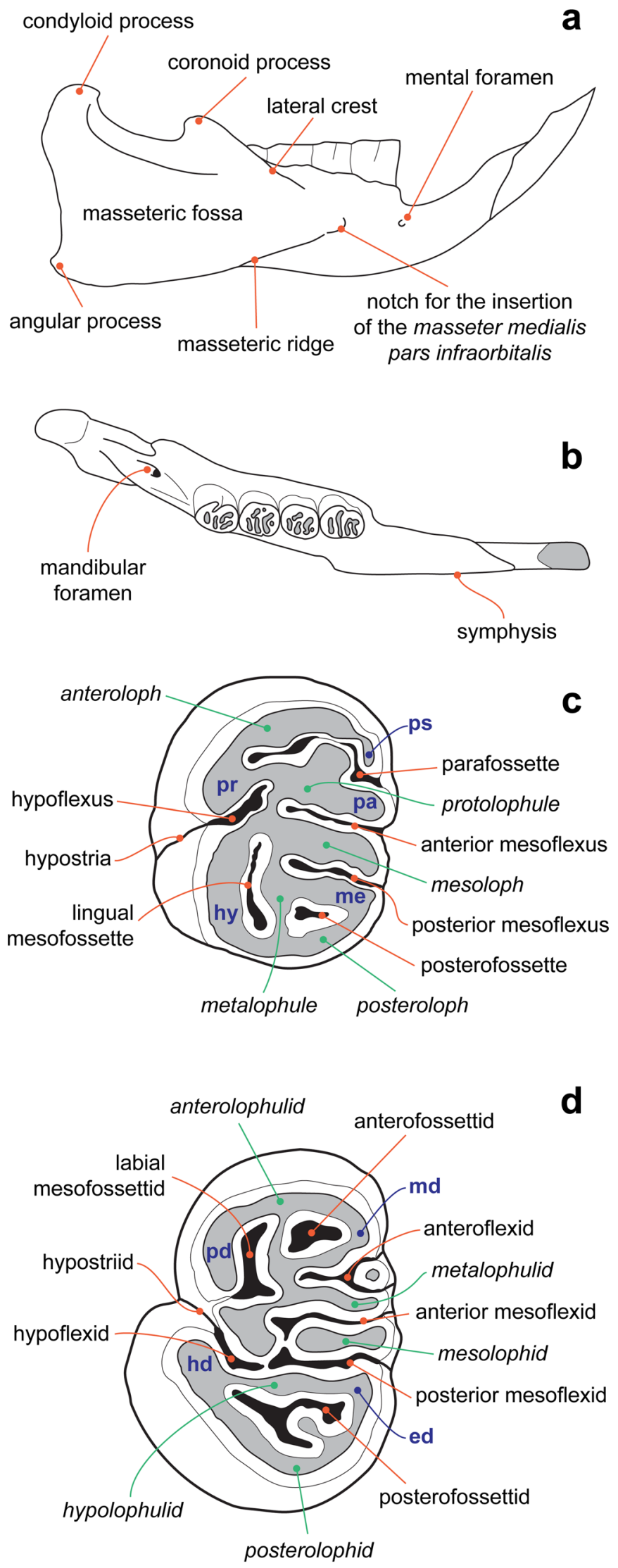
several cranial and postcranial linear measurements of rodents (mainly hystricomorphs). We decided to use their equation based on the $\mathrm{m} 1$ length to estimate the body mass of extinct porcupine species because: (1) the $\mathrm{m} 1$ length the variable for which we had the most abundant dataset; and (2) we verified the high accuracy of the equation by applying it for the extant $H$. cristata and $H$. africaeaustralis, obtaining body mass values extremely close to the actual ones for these two species as reported in the literature (see Discussion). The prediction equation is as follows:

$B M=10^{\wedge}\left[\left(2.902 \times \log _{10 m} 1 L\right)+1.434\right] / 1000$

where $\mathrm{BM}$ is the body mass $(\mathrm{kg})$ and $\mathrm{m} 1 \mathrm{~L}$ is the $\mathrm{m} 1$ length $(\mathrm{mm})$.

Institutional abbreviations: DNMNH, Ditsong Museum of Natural History, Pretoria; ESI, Evolutionary Studies Institute, University of the Witwatersrand, Johannesburg; ISEM, Institute of Evolutionary Science of Montpellier; LCOG, Leakey Camp Olduvai Gorge; NHM, Natural History Museum, London; NME, National Museum of Ethiopia, Addis Ababa; NMK, National Museums of Kenya, Nairobi; NMT, National Museum of Tanzania, Dar es Salaam; THOR, Tanzania Human Origins Research.

\section{Systematic Paleontology}

Class MAMMALIA Linnaeus, 1758

Order RODENTIA Bowdich, 1821

Family HYSTRICIDAE Fischer von Waldheim, 1817

Subfamily HYSTRICINAE Fischer von Waldheim, 1817

Genus Hystrix Linnaeus, 1758

Hystrix makapanensis Greenwood, 1958

Holotype ESI M1002, left mandibular fragment with i1 (fragmented), $\mathrm{p} 4$, and mesial part of $\mathrm{m} 1$.

Type Locality Makapansgat Limeworks, South Africa (late Pliocene-earliest Pleistocene).

Geographical Occurrence East (Ethiopia, Kenya, Tanzania) and South Africa.

Chronological Occurrence Early Pliocene (late Zanclean) to Early Pleistocene (early Calabrian).

Emended Diagnosis Hystrix with low frontal bone inflation. The mandibular corpus is massive. The mandibular diastema is robust. The masseteric ridge is oblique and extends anteriorly below the contact between $\mathrm{p} 4$ and $\mathrm{m} 1$; the lateral crest is shelf-like; the masseteric ridge and lateral crest meets anteriorly in a wide notch for the insertion of the masseter medialis pars infraorbitalis. The mandibular foramen is wide and located into a deep longitudinal groove. Upper and lower cheek teeth are hypsodont. Upper cheek teeth have marked apical curvature. Normally, the deep posterior mesoflexus joins the lingual mesofossette forming a L-shaped islet. In P4 (and dP4) with low to medium wear, the strong anterior mesoflexus joins the hypoflexus bisecting the tooth into mesial and distal lobes. The M1 and M2 are almost circular in occlusal outline. The M3 is wide mesially and narrow distally. The i1 is robust and sub-triangular in section, with rounded edges in occlusal view; it emerges little from the alveolus (i.e., its tip is about at the same level of the posterior margin of the diastema in labial view). The p4 is the largest tooth in the lower row; it is massive and trapezoidal in occlusal view, with well-developed hypoflexid and posterior mesoflexid; in moderately worn teeth, these folds are joined to form a continuous groove that divides the tooth into similar-sized mesial and distal lobes; these folds correspond respectively to deep hypostriid and posterior mesostriid, with the latter crossing vertically the entire crown height. The $\mathrm{m} 1$ is the smallest tooth of the lower row.

Differential Diagnosis Temporal lines on the parietals are robust and do not converge to form a sagittal crest, whereas adult $H$. africaeaustralis and $H$. cristata have a prominent sagittal crest). Mandibular corpus is more gracile and less curved than in X. crassidens. The mandibular diastema is not as short or as strongly curved as in $X$. crassidens. Upper and lower cheek teeth are about 30\% larger than extant African species and have well-developed roots covered by cementum, whereas extant African species only develop small, papillate, enamel-unsheathed root projections, and $X$. crassidens has robust and elongated roots. The occlusal pattern of cheek teeth is overall more complex than in extant African species (especially $H$. cristata) and $X$. crassidens. The $\mathrm{m} 1$ is not as small as in extant African species, in which it is significantly smaller than the other teeth.

Referred Material LCOG THOR15\#81, right hemimandible with fragmented i1, complete $\mathrm{p} 4-\mathrm{m} 2$, and $\mathrm{m} 3$ alveolus (Fig. 2, Online Resource 1).

Locality and Age Olduvai Gorge, Site HWK-W.

Henrietta Wilfrida Korongo West (HWK-W; Geolocality 44, Hay 1976) is located in the southwestern part of the Junction Area (i.e., the intersection between the Main Gorge and Side Gorge; Fig. 3), in the marginal zone of Palaeolake Olduvai, few hundred meters west from HWK-E, one of the best-known archaeological sites in Olduvai (Leakey 1971). This last site and the nearby HWK-EE have been thoroughly investigated in the last decades and yielded considerable 


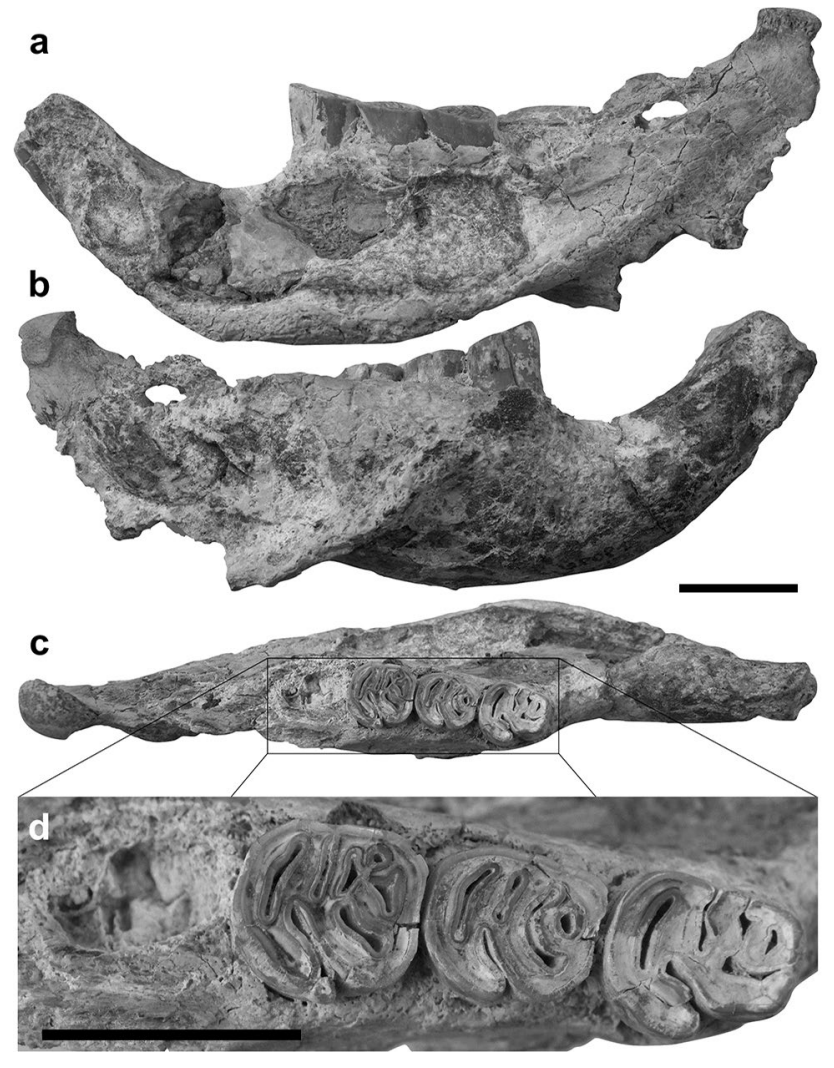

Fig. 2 Hystrix makapanensis from Olduvai Gorge (Tanzania), site HWK-W. Left hemimandible LCOG THOR15\#81 in lingual (a), labial (b), and occlusal (c) views. d Close-up of lower cheek teeth. Scale bars equal $20 \mathrm{~mm}$

quantities of fossils, stone artifacts, and plant macrofossils (Albert et al. 2018; de la Torre et al. 2018). The Olduvai stratigraphic succession spans about $2 \mathrm{Ma}$ and includes $60-70 \mathrm{~m}$ of alternating lacustrine, fluvial, and volcaniclastic sediments whose deposition was controlled by the transgression/regression dynamics of Palaeolake Olduvai, the setting/ modification of river drainage systems, and the activity of the surrounding Ngorongoro Volcanic Complex (Hay 1976). Soils also occur within the sequence. Geolocality 44 is one of the Olduvai places where the full stratigraphic succession (Bed I-IV, Masek, Ndutu, and Naisiusiu Beds, from bottom to top) is exposed (Hay 1976). In recent years, this locality has been extensively analyzed by Stanistreet et al. (2018) and Uribelarrea et al. (2019; as "LTK").

LCOG THOR15\#81 was collected during surface survey right at the bottom of Geolocality 44 outcrop, i.e., out of its original stratigraphic context. However, its taphonomic features give some clues about its provenance. Prior to preparation, the specimen was almost completely encrusted by carbonate concretions showing an irregular and pitted surface (Online Resource 1). In some parts, longitudinal and transversal cracks filled with carbonates crossed the concretion and formed an alveolar pattern, indicating repeated phases of alteration/dissolution/reprecipitation resulting from pedogenesis. Apparently, these multi-generational cracks derive from long exposure and weathering processes, connected to the transgression/regression cycles of Palaeolake Olduvai (Hay 1976; Bennett et al. 2012). The overall appearance of LCOG THOR15\#81 resembled closely the micritic nodules with desiccation cracks described by Bennett et al. (2012) in their compendium on carbonate horizons from Olduvai Bed I-II. In Geolocality 44, these pedofeatures occur in the lower part of the succession, between Tuff IF and the Lower Augitic Sandstone, i.e., within the lowermost part of Bed II (Bennett et al. 2012; Stanistreet et al. 2018; Uribelarrea et al. 2019). Following the most recent available dates (Stanistreet et al. 2020), the specimen can therefore be dated to about 1.8-1.7 Ma.

Description The right hemimandible LCOG THOR15\#81 (Fig. 2, Online Resource 1) is overall well preserved, although it lacks the coronoid and angular processes. Only a basal fragment of the $\mathrm{i} 1$ is preserved and the $\mathrm{m} 3$ is missing. The absence of evidence of alveolar resorption suggests that it was lost during the life of the animal or soon after its death. The corpus is robust on the whole. It appears elongated in occlusal view and with a crescent-moon shape in labial and lingual views. At the dorsal tip of the ramus, the condyloid process is preserved; it is moderately convex and shows a rounded outline in dorsal view. The mandibular foramen is faintly visible on the lingual side of the ramus and is located posteriorly to the $\mathrm{m} 3$ alveolus. The internal pterygoid fovea is narrow and deeply concave. Labially, the posterior portion of the masseteric fossa is missing. The fossa is markedly concave and its masseteric ridge is pronounced and almost straight. It runs obliquely from the ventral margin of the fossa upward through the corpus, ending at the limit between $\mathrm{p} 4$ and $\mathrm{m} 1$. The masseteric ridge protrudes labially in occlusal view. The lateral crest is strong and has also a shelf-like shape. In occlusal view, the notch for the insertion of the masseter medialis pars infraorbitalis is wide and located below the distal half of the $\mathrm{p} 4$. The symphysis is sub-rectangular in lingual view. Posteroventrally to the symphysis, the ventral surface of the corpus forms a protruding shelf, well visible in occlusal view, which extends posteriorly up to the distal end of the $\mathrm{m} 2$ and hosts the long root of the lower incisor. The mandibular diastema is shorter than the p4-m3 length and is strongly curved dorsally, especially in the anterior part. In labial view, no mental foramina are visible due to some sediment crusts still covering the anterior portion of the corpus. This last part of the mandible is notably thick. In labial view, the p4 is well visible, while the $\mathrm{m} 1$ and $\mathrm{m} 2$ are covered for most of their height by the dorsal margin of the corpus. In occlusal view, the lower cheek teeth exhibit a roughly similar width (i.e., the lingual and labial outlines of the tooth row are sub-parallel). 
Fig. 3 Geographical distribution Hystrix makapanensis. a Location of the African paleontological sites in which the species is reported. Locality numbers: 1 , Makapansgat Limeworks (type locality); 2, Gondolin; 3, Kromdraai, Swartkrans, Sterkfontein; 4, Olduvai Gorge; 5, Laetoli; 6, Chemeron; 7, Omo Shungura; 8 , Hadar. The present-day geographical ranges of Hystrix cristata (red) and Hystrix africaeaustralis (green) are shown in the background (data from Kingdon 2015).

The two species are currently sympatric in most Tanzania. b Map of Olduvai Gorge (redrawn from Jorajev et al. 2016) with location of the sites mentioned in the text. Abbreviations: FLK, Frida Leakey Korongo; HWK, Henrietta Wilfrida Korongo; MK, Maccinnes Korongo

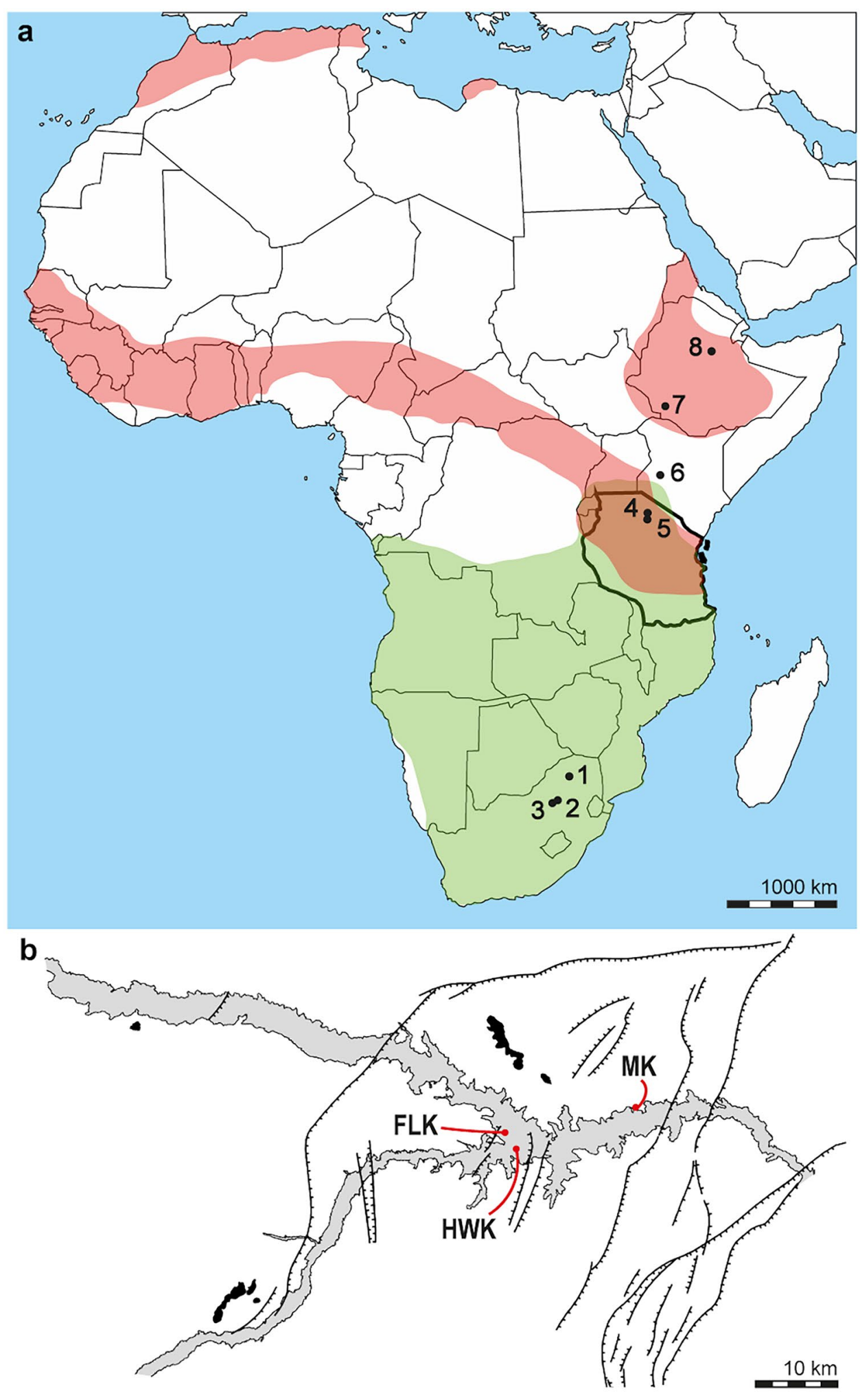

The $\mathrm{p} 4$ is high crowned and trapezoidal in occlusal outline (i.e., the distal wall is wider than the mesial and the latter forms distinct angles with the labial and lingual ones). In occlusal view, the hypoflexid is deep and directed distally with an angle of about $45^{\circ}$ with respect to the main axis of the tooth. This sinusid corresponds to a deep hypostriid crossing vertically the whole labial wall of the crown. Lingually, four folds are visible in occlusal view. The anterofossettid is shaped as an enamel islet not connected to the outer edge of the tooth; it is elongated labiolingually, tapers 
labially, and is slightly convex toward the mesial side. The anterior mesoflexid is a lingually opened fold with a Y shape; its inner border does not reach the inner end of the anterofossettid. The labial mesofossettid is an elongated islet that tapers mesially almost reaching the mesial border of the tooth. The posterior mesoflexid opens at about half length of the lingual margin and runs up to the midline of the tooth, thus being longer than the anterior mesoflexid. Lingually, the posterior mesostriid is well visible and crosses the entire crown height. The simple-shaped posterofossettid is elongated labiolingually and does not open on the lingual border of the tooth; it is slightly convex in the distal direction. Mesially, between the mesial edge of the tooth and the anterofossettid, the small anterolophulid is bisected by the labial mesofossettid. Relatively thick metalophulid and mesolophid develop between the anterofossettid and anterior mesoflexid and between the anterior and posterior mesoflexid, respectively. The narrow hypolophulid is constricted between the distal margin of the hypoflexid and the posterofossettid. Distally, the posterolophid is a well-developed U-shaped lophid crossing the entire crown labiolingually. A large protoconid develops mesiolabially, between the labial sinusid and labial mesofossettid. Mesiolingually, the metaconid is relatively small, about half the size of the protoconid. The hypoconid, located distal to the labial sinusid, is the largest cuspid. The entoconid, included between the posterior mesoflexid and posterofossettid, is also robust.

The $\mathrm{m} 1$ is the smallest of the preserved teeth. Its crown is lower than that of the $\mathrm{p} 4$ and has a relatively more rounded occlusal surface. In labial view, the hypostriid is partially covered by a crust so it is not possible to check whether it reaches the crown base. In occlusal view, it develops as a long hypoflexid directed distolingually, parallel to that of the $\mathrm{p} 4$. No folds open on the lingual wall, but they appear as four enamel islets. Mesially, the anterofossettid is small and rounded. The anterior mesoflexid is fused with the labial mesofossettid in a single, U-shaped enamel islet, constricted in the middle. The posterior mesoflexid is slightly inclined distolabially and also exhibits a middle constriction. The posterofossettid is elongated and mesially concave. The metaconid is slightly larger than the protoconid. The latter is more rounded than that of the $\mathrm{p} 4$. The hypoconid is well developed, but slenderer and more pointed than that of the p4. Compared to the latter, the entoconid is smaller, whereas the lophids are similarly developed.

The $\mathrm{m} 2$ is larger than the $\mathrm{m} 1$ and shows a more squarish occlusal outline. The hypoflexid is well developed and distally enlarged. The corresponding hypostriid is deep and crosses vertically the entire crown labial wall. Labially to the hypoflexid, out from the edge of the tooth, a small and rounded enamel islet, the ectostylid, develops. The labial mesofossettid is well developed and runs distolingually with a middle constriction, as observed in the $\mathrm{m} 1$. On the lingual side, the main folds form four islets, none of which open lingually. The anterofossettid and anterior mesoflexid are similar in size and both have $\mathrm{Y}$ shape. The distal tip of the former is merged with the mesial tip of the latter and, in turn, they are fused with a circular additional islet placed lingually. The posterior mesoflexid touches the lingual edge of the tooth. Both this fold and the posterofossettid are long and slender like those of the p4 and $\mathrm{m} 1$. Mesially, the mesolophid is narrow and the metalophulid is absent due to the development of the aforementioned mesiolingual enamel islets. All main cuspids are less developed than those of the $\mathrm{m} 1$.

\section{Review of the African Record of $\boldsymbol{H}$. makapanensis}

All the material described in this section is listed in Table 1. All dental measurements are reported in Online Resource 3.

\section{South Africa}

Makapansgat, Members 3-4 The Makapansgat Valley is a world-famous Plio-Pleistocene site (Fig. 3) which yielded abundant vertebrate remains including australopithecines (Herries et al. 2013). The Valley hosts several caves, of which the earliest is the Makapansgat Limeworks Cave, whose stratigraphy is divided into four members (Partridge 1979; Latham et al. 1999; Herries et al., 2013). In this section, we focus on members 3-4, spanning in age the interval 3.03-2.58 Ma (Herries et al. 2013).

Greenwood $(1955,1958)$ reported the occurrence of three porcupine species in Makapansgat Member 3. Alongside the extant $H$. africaeaustralis (27 specimens referred to at least five individuals), she recognized two, previously unknown forms which she referred to the new species $X$. crassidens (44 specimens, eight individuals) and $H$. makapanensis (only 10 specimens representing five individuals; Adams 2012b). The latter was first diagnosed based on two mandibles, the holotype ESI M1002 and the paratype ESI M1003 (Greenwood 1955). The species was initially named as Hystrix major by Greenwood (1955) but in a subsequent paper, Greenwood (1958) revised the specific name to $H$. makapanensis, as $H$. major was determined as being a junior homonym of $H$. major Gervais, 1859, a fossil porcupine from the Plio-Pleistocene of Europe (now referred to Hystrix refossa Gervais, 1852; van Weers and Rook 2003). In a later treatment on South African hystricids, Maguire (1976, 1978) re-assigned the paratype ESI M1003 to X. crassidens and also attributed additional hystricid craniodental specimens from Makapansgat members 3 and 4 to $H$. makapanensis, including provisionally attributing the first maxillary teeth (ESI M1812 and ESI M8220) to the species after noting the presence of 
Table 1 African record of Hystrix makapanensis. See Adams (2012b) for the list of postcranial material from Gondolin. Abbreviations: ULB, Upper Laetolil Beds; UNB, Upper Ndolanya Beds

\begin{tabular}{|c|c|c|c|c|c|c|c|}
\hline Repository & ID & Country & Site & Stratigraphy & Material & Side & Notes \\
\hline ESI & M1002 & South Africa & Makapansgat & Member 3 & $\begin{array}{l}\text { Mandible with i1 (frag.), } \\
\text { p4, m1 (frag.) }\end{array}$ & $\mathrm{L}$ & \\
\hline ESI & M1811 & South Africa & Makapansgat & Member 3 & $\mathrm{p} 4$ & $\mathrm{R}$ & \\
\hline ESI & M1812 & South Africa & Makapansgat & Member 3 & P4 & $\mathrm{L}$ & \\
\hline ESI & M1815 & South Africa & Makapansgat & Member 3 & $\mathrm{p} 4$ & $\mathrm{~L}$ & \\
\hline ESI & M2526 & South Africa & Makapansgat & Member 3 & I1 (frag.) & $\mathrm{L}$ & \\
\hline ESI & M8220 & South Africa & Makapansgat & Member 4 & P4 & & \\
\hline ESI & M8282 & South Africa & Makapansgat & Member 4 & $\begin{array}{l}\text { Mandible with i1 (frag.), } \\
\text { dp4 (broken roots), } \\
\text { m1-m2 }\end{array}$ & $\mathrm{L}$ & \\
\hline DNMNH & G11987 & South Africa & Gondolin & GD 2 & Cranium (frontal frag.) & & \\
\hline DNMNH & G12034 & South Africa & Gondolin & GD 2 & Cranium (neurocranium) & & $\begin{array}{l}\text { Associated with } \\
\text { G11987, G12087, } \\
\text { G12143 }\end{array}$ \\
\hline DNMNH & G12087 & South Africa & Gondolin & GD 2 & Maxilla with P4-M3 & $\mathrm{L}$ & Antimere to G12143 \\
\hline DNMNH & G12137 & South Africa & Gondolin & GD 2 & $\begin{array}{l}\text { Maxilla with erupting } \\
\text { dP4, M1 }\end{array}$ & $\mathrm{R}$ & Associated with G13164 \\
\hline DNMNH & G12143 & South Africa & Gondolin & GD 2 & $\begin{array}{l}\text { Maxilla with incisor } \\
\text { alveoli, P4-M3 }\end{array}$ & $\mathrm{R}$ & Antimere to G12087 \\
\hline DNMNH & G12185 & South Africa & Gondolin & GD 2 & Cranium (parietal) & & \\
\hline DNMNH & G1316 & South Africa & Gondolin & GD 2 & Indet. molar crown & & \\
\hline DNMNH & G13164 & South Africa & Gondolin & GD 2 & $\begin{array}{l}\text { I1 (frag.) with part of the } \\
\text { diastema }\end{array}$ & $\mathrm{L}$ & \\
\hline DNMNH & G22146 & South Africa & Gondolin & GD 2 & i1 (frag.) & $\mathrm{L}$ & \\
\hline DNMNH & G22147 & South Africa & Gondolin & GD 2 & M1 (frag.) & $\mathrm{L}$ & \\
\hline DNMNH & G22148 & South Africa & Gondolin & GD 2 & M2 & $\mathrm{L}$ & \\
\hline DNMNH & G4800 & South Africa & Gondolin & GD 2 & i1 (frag.) & $\mathrm{L}$ & Antimere to G4971 \\
\hline DNMNH & G4971 & South Africa & Gondolin & GD 2 & i1 & $\mathrm{R}$ & Antimere to G4800 \\
\hline DNMNH & G9643 & South Africa & Gondolin & GD 2 & I1 & $\mathrm{R}$ & \\
\hline DNMNH & GA11 & South Africa & Gondolin & GD A & M1 & $\mathrm{R}$ & \\
\hline DNMNH & GA50 & South Africa & Gondolin & GD A & M3? & $\mathrm{L}$ & \\
\hline DNMNH & GA7 & South Africa & Gondolin & GD A & $\mathrm{p} 4$ & $\mathrm{~L}$ & $\begin{array}{l}\text { Possibly same individual } \\
\text { as GA50 }\end{array}$ \\
\hline DNMNH & GA839 & South Africa & Gondolin & GD A & Mandible with p4 & $\mathrm{L}$ & \\
\hline DNMNH & KA1912 & South Africa & Kromdraai & A & M3 & $\mathrm{R}$ & cf. \\
\hline DNMNH & KA1432 & South Africa & Kromdraai & A & $\begin{array}{l}\text { Mandible with i1, dp4, } \\
\text { just erupted m3 }\end{array}$ & $\mathrm{R}$ & cf. \\
\hline DNMNH & SK14237 & South Africa & Swartkrans & Member 1 & $\mathrm{p} 4$ & $\mathrm{~L}$ & cf. \\
\hline DNMNH & SK2466 (A/B) & South Africa & Swartkrans & Member 1 or 2 & M3 (A) and M2 (B) & $\mathrm{R}$ & cf. \\
\hline DNMNH & SKX14286 & South Africa & Swartkrans & Member 1 or 2 & Indet. lower cheek tooth & & cf. \\
\hline DNMNH & SFN15 & South Africa & Sterkfontein & Dump 8 & $\mathrm{P} 4$ & $\mathrm{R}$ & cf. \\
\hline DNMNH & SFN17 & South Africa & Sterkfontein & Dump 10 & M1/M2 & $\mathrm{R}$ & cf. \\
\hline DNMNH & SE1263.1 & South Africa & Sterkfontein & Member 5 & $\begin{array}{l}\text { Mandible with dp4 } \\
\text { (frag.), m1, erupting } \\
\text { m2 }\end{array}$ & $\mathrm{R}$ & $\begin{array}{l}\text { cf.-Possibly same indi- } \\
\text { vidual as SE1255.1 }\end{array}$ \\
\hline DNMNH & SE1255.1 & South Africa & Sterkfontein & Member 5 & Mandible with $\mathrm{m} 1-\mathrm{m} 2$ & $\mathrm{~L}$ & cf. \\
\hline ISEM & 874 & Tanzania & Olduvai Gorge & $\begin{array}{l}\text { FLK-N, Bed 1, } \\
1-2-3\end{array}$ & Mandible with dp4-m2 & $\mathrm{R}$ & Antimere to 6031 \\
\hline ISEM & 6031 & Tanzania & Olduvai Gorge & $\begin{array}{l}\text { FLK-N, Bed 1, } \\
1-2-3\end{array}$ & Mandible with dp4-m2 & $\mathrm{L}$ & Antimere to 874 \\
\hline ISEM & H.1 & Tanzania & Olduvai Gorge & FLK-N, Bed 1, 1 & $\mathrm{dp} 4$ & $\mathrm{R}$ & \\
\hline ISEM & H.10a & Tanzania & Olduvai Gorge & $\begin{array}{l}\text { FLK-N, Bed 1, } \\
1-2-3\end{array}$ & I1 & $\mathrm{L}$ & \\
\hline
\end{tabular}


Table 1 (continued)

\begin{tabular}{|c|c|c|c|c|c|c|c|}
\hline Repository & ID & Country & Site & Stratigraphy & Material & Side & Notes \\
\hline ISEM & H.10b & Tanzania & Olduvai Gorge & $\begin{array}{l}\text { FLK-N, Bed 1, } \\
1-2-3\end{array}$ & I1 & $\mathrm{R}$ & \\
\hline ISEM & H.3 & Tanzania & Olduvai Gorge & FLK-N, Bed 1, 1 & Maxilla with M1-M2 & $\mathrm{R}$ & $\begin{array}{l}\text { Possibly same individual } \\
\text { as H.9 }\end{array}$ \\
\hline ISEM & H.4 & Tanzania & Olduvai Gorge & $\begin{array}{l}\text { FLK-N, Bed 1, } \\
1-2-3\end{array}$ & M1 & $\mathrm{R}$ & $\begin{array}{l}\text { Possibly same individual } \\
\text { as H.5, H.6, H10a-b }\end{array}$ \\
\hline ISEM & H.5 & Tanzania & Olduvai Gorge & $\begin{array}{l}\text { FLK-N, Bed 1, } \\
1-2-3\end{array}$ & P4 & $\mathrm{L}$ & \\
\hline ISEM & H.6 & Tanzania & Olduvai Gorge & $\begin{array}{l}\text { FLK-N, Bed 1, } \\
1-2-3\end{array}$ & M1 & $\mathrm{L}$ & \\
\hline ISEM & H.7 & Tanzania & Olduvai Gorge & $\begin{array}{l}\text { FLK-N, Bed 1, } \\
1-2-3\end{array}$ & $\mathrm{dP} 4$ & $\mathrm{R}$ & $\begin{array}{l}\text { Possibly same individual } \\
\text { as H.8 }\end{array}$ \\
\hline ISEM & H.8 & Tanzania & Olduvai Gorge & $\begin{array}{l}\text { FLK-N, Bed 1, } \\
1-2-3\end{array}$ & $\mathrm{dP} 4$ & $\mathrm{~L}$ & \\
\hline ISEM & H.9 & Tanzania & Olduvai Gorge & FLK-N, Bed 1, 1 & $\begin{array}{l}\text { Mandible with left i1-m3, } \\
\text { right i1-m2 }\end{array}$ & $\mathrm{L}+\mathrm{R}$ & \\
\hline ISEM & n.a & Tanzania & Olduvai Gorge & $\begin{array}{l}\text { FLK-N, Bed 1, } \\
\text { n.a }\end{array}$ & i1 & $\mathrm{L}$ & Associated with 6031 \\
\hline LCOG & THOR15\#81 & Tanzania & Olduvai Gorge & $\begin{array}{l}\text { HWK-W, Lower } \\
\text { Bed II }\end{array}$ & Mandible with p4-m2 & $\mathrm{R}$ & \\
\hline NHM & M16593 & Tanzania & Olduvai Gorge & HWK, Bed 1 & $\begin{array}{l}\text { Mandible with } \mathrm{m} 1, \mathrm{~m} 2 \text {, } \\
\text { erupting } \mathrm{m} 3\end{array}$ & $\mathrm{R}$ & \\
\hline NHM & M16594 & Tanzania & Olduvai Gorge & MK, Bed 1 & M1/M2 & $\mathrm{R}$ & \\
\hline NHM & M16595 & Tanzania & Olduvai Gorge & MK, Bed 1 & I1 (frag.) & & \\
\hline NMT & LAET74-256 & Tanzania & Laetoli & $\begin{array}{l}\text { Loc. 3, Laetolil } \\
\text { Beds }\end{array}$ & M3 & $\mathrm{L}$ & \\
\hline NMT & LAET75-1971 (R1) & Tanzania & Laetoli & $\begin{array}{l}\text { Loc. 10, Laetolil } \\
\text { Beds }\end{array}$ & M3 & $\mathrm{L}$ & \\
\hline NMT & EP1996/00 & Tanzania & Laetoli & $\begin{array}{l}\text { Loc. 5, ULB btw } \\
\text { Tuff 3-5 }\end{array}$ & M3 & $\mathrm{R}$ & \\
\hline NMT & EP2015/00 & Tanzania & Laetoli & $\begin{array}{l}\text { Loc. } 6 \text {, ULB btw } \\
\text { Tuff 3-5 }\end{array}$ & $\mathrm{p} 4$ & $\mathrm{R}$ & \\
\hline NMT & EP329/00 & Tanzania & Laetoli & $\begin{array}{l}\text { Loc. 8, ULB btw } \\
\text { Tuff 5-7 }\end{array}$ & $\begin{array}{l}\text { Left P4-M2 and right } \\
\text { P4-M1 }\end{array}$ & $\mathrm{L}+\mathrm{R}$ & \\
\hline NMT & EP3354/00 & Tanzania & Laetoli & $\begin{array}{l}\text { Loc. 15, ULB } \\
\text { btw Tuff 6-7 }\end{array}$ & M3 & $\mathrm{L}$ & \\
\hline NMT & EP988/00 & Tanzania & Laetoli & Loc. $18, \mathrm{UNB}$ & Mandible with p4-m2 & $\mathrm{L}$ & \\
\hline NMT & EP086/03 & Tanzania & Laetoli & Loc. $18, \mathrm{UNB}$ & M1/M2 & $\mathrm{L}$ & \\
\hline NMT & EP655/05 & Tanzania & Laetoli & $\begin{array}{l}\text { Loc. 6, ULB btw } \\
\text { Tuff 5-7 }\end{array}$ & Mandible with $\mathrm{p} 4-\mathrm{m} 2$ & $\mathrm{~L}$ & \\
\hline NMT & EP1070/16 & Tanzania & Laetoli & $\begin{array}{l}\text { Loc. 9, ULB btw } \\
\text { Tuff 5-8 }\end{array}$ & M1/M2 & $\mathrm{R}$ & \\
\hline NMT & EP255/14 & Tanzania & Laetoli & Loc. $15, \mathrm{UNB}$ & $\begin{array}{l}\text { Mandible with i1 (frag.), } \\
\text { p4-m2, m3 (frag.) }\end{array}$ & $\mathrm{L}$ & \\
\hline NMK & KNM-BC432 & Kenya & Chemeron & Chemeron Fm & Mandible with p4 & $\mathrm{L}$ & \\
\hline NME & L65-35 & Ethiopia & Omo Shungura & Member G & M1/M2 & $\mathrm{R}$ & \\
\hline ISEM & OMO243.1973.4838 & Ethiopia & Omo Shungura & Member G & M1/M1 & $\mathrm{R}$ & \\
\hline ISEM & L628-228 & Ethiopia & Omo Shungura & Member G & M1/M2 & $\mathrm{L}$ & \\
\hline ISEM & L627-154 & Ethiopia & Omo Shungura & Member G & $\mathrm{m} 1 / \mathrm{m} 2$ & $\mathrm{~L}$ & \\
\hline NME & A.L.265-9 & Ethiopia & Hadar & Submember SH-2 & $\mathrm{m} 1$ & $\mathrm{~L}$ & $\mathrm{cf}$. \\
\hline
\end{tabular}


labial enamel folds that yield a bifurcated appearance to the crown as noted on the $\mathrm{p} 4$ (Greenwood 1955). As a matter of fact, the initial diagnosis of $H$. makapanensis is quite uninformative, as it identifies the species simply as "an extinct Hystrix with cheek teeth approximately one third larger than Hystrix africaeaustralis" (Greenwood 1955: 78). Maguire (1976) provided the first set of formal diagnostic criteria for H. makapanensis that went beyond Greenwood's original size-based diagnosis: (1) the p4 exhibits a deep, centrallypositioned lingual groove (here called posterior mesostriid) that persists from the crown apex to the alveolar rim; (2) the lingual sinusid (here called posterior mesoflexid) meets a distinct labial sinusid (here called hypoflexid) particularly towards the apex, such that the $\mathrm{p} 4$ is internally divided into mesial and distal lobes of roughly equal size; (3) the mandibular corpus is more robust than that of $H$. africaeaustralis, but more gracile than that of $X$. crassidens; (4) the mandibular diastema is also not as deep, short, or as strongly curved as in X. crassidens (see also Collings et al. 1976). In addition, Maguire (1976) also noticed that H. makapanensis premolars and molars have well-formed, cementumcovered roots that project from the enamel-unsheathed body of the crown within the alveolus. The premolars and molars of extant $H$. africaeaustralis typically only develop small, papillate, enamel-unsheathed root projections from the crown, while $X$. crassidens teeth have very robust, elongated roots. Moreover, the upper cheek teeth of H. makapanensis exhibit a stronger apical curvature and hypsodonty relative to those of $X$. crassidens. Although statistics were not provided, Maguire (1976) confirmed that the cheek teeth of $H$. makapanensis are roughly $1 / 3$ larger than those of fossil and extant $H$. africaeaustralis but somewhat smaller than those of $X$. crassidens.

The holotype ESI M1002 (Fig. 4) is the anterior portion of a left hemimandible including a basal fragment of i1, complete $\mathrm{p} 4$, and mesial portion of the $\mathrm{m} 1$. In labial view, the anterior portion of the corpus is notably thick and robust. The diastema smoothly curves dorsally in the anterior part but runs straight in the posterior one, where it forms a right angle with the alveolar swelling of the p4. Two mental foramina are visible, a larger one below the mesial margin of p4 and a smaller one below the distal half of the same tooth. In lingual view, the symphysis seems sub-rectangular though the posterior part is broken. The il is broken at the crown base and only the mesial margin is still visible; however, in posterior view, the fragmentation of the corpus exposes the section of the i1, which is sub-triangular with rounded edges. The $\mathrm{p} 4$ is high crowned and trapezoidal in occlusal shape, with the mesial margin wider than the distal one. The posterior mesostriid is deep and crosses vertically the whole lingual wall of the tooth, as opposed to the hypostriid which is deep in the apical part but shallower toward the root. In occlusal view, no folds are open on the outer

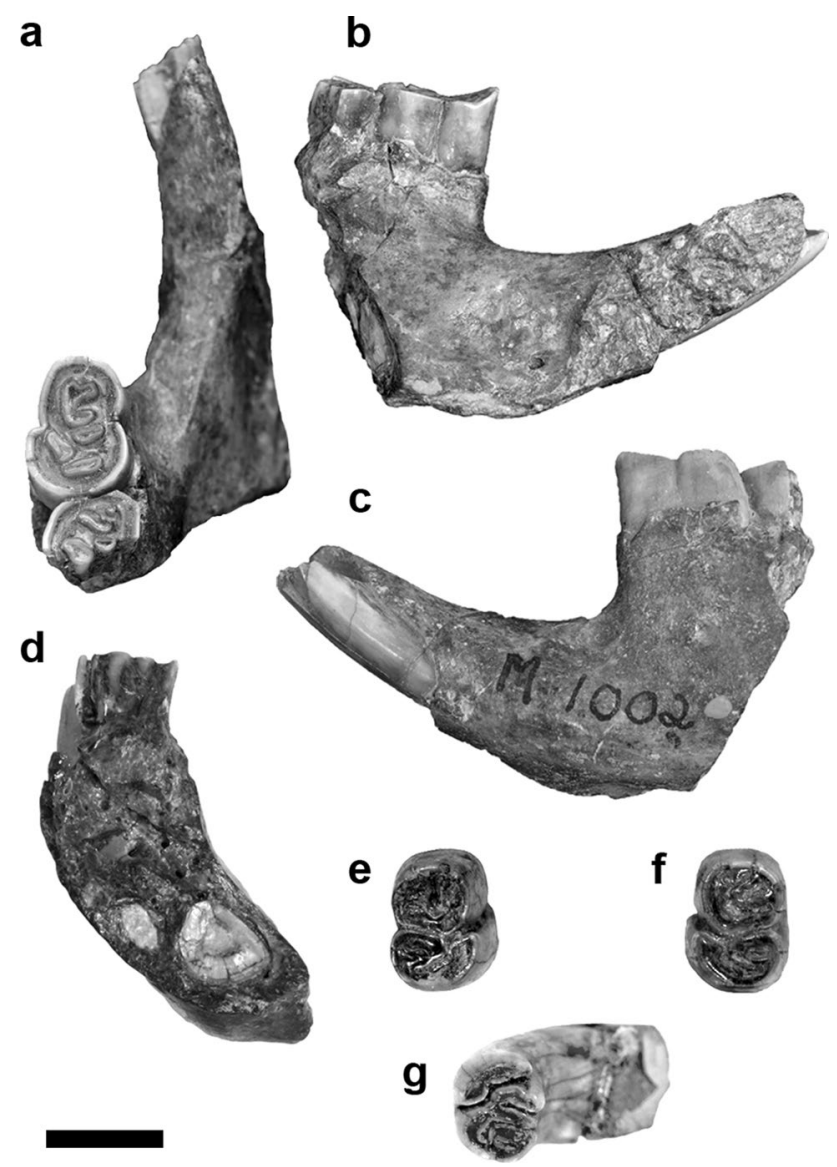

Fig. 4 Hystrix makapanensis from the type locality of Makapansgat Limeworks, members 3-4 (South Africa). a-d Holotype, left hemimandible with fragmented i1, p4, and fragmented m1 ESI M1002 in occlusal (a), lingual (b), labial (c), and posterior (d) views. e Right p4 ESI M1811 in occlusal view. f Left p4 ESI M1815 in occlusal view. $\mathbf{g}$ Left P4 ESI M1812 in occlusal view. Scale bar equals $10 \mathrm{~mm}$

margin of the crown. The anteroflexid, labial mesofossettid, and anterior mesoflexid form a single $\mathrm{C}$-shaped islet. The hypoflexid is obliquely oriented toward the distal side. The posterior mesoflexid is similar in size to the hypoflexid. The posterofossettid is the most elongated fold. The protoconid and metaconid are similar in size and are both smaller than the entoconid and hypoconid. The latter is the most developed cuspid. The anterolophulid is slightly thicker than the posterolophid, whereas all other lophids are relatively more constricted mesiodistally. The size of the $\mathrm{p} 4$ is close to that of LCOG THOR15\#81, falling in the upper part of the $H$. makapanensis range (Fig. 5).

The right p4 ESI M1811 (Fig. 4) shows on the labial surface a faint anterostriid and a better visible posterior mesostriid, with the latter that persists from the crown apex to the alveolar rim. Occlusally, the posterior mesoflexid joins the hypoflexid, dividing the tooth into mesial and distal lobes (see Maguire 1976). Labially, a centrally-positioned hypostriid is deep and marked. 

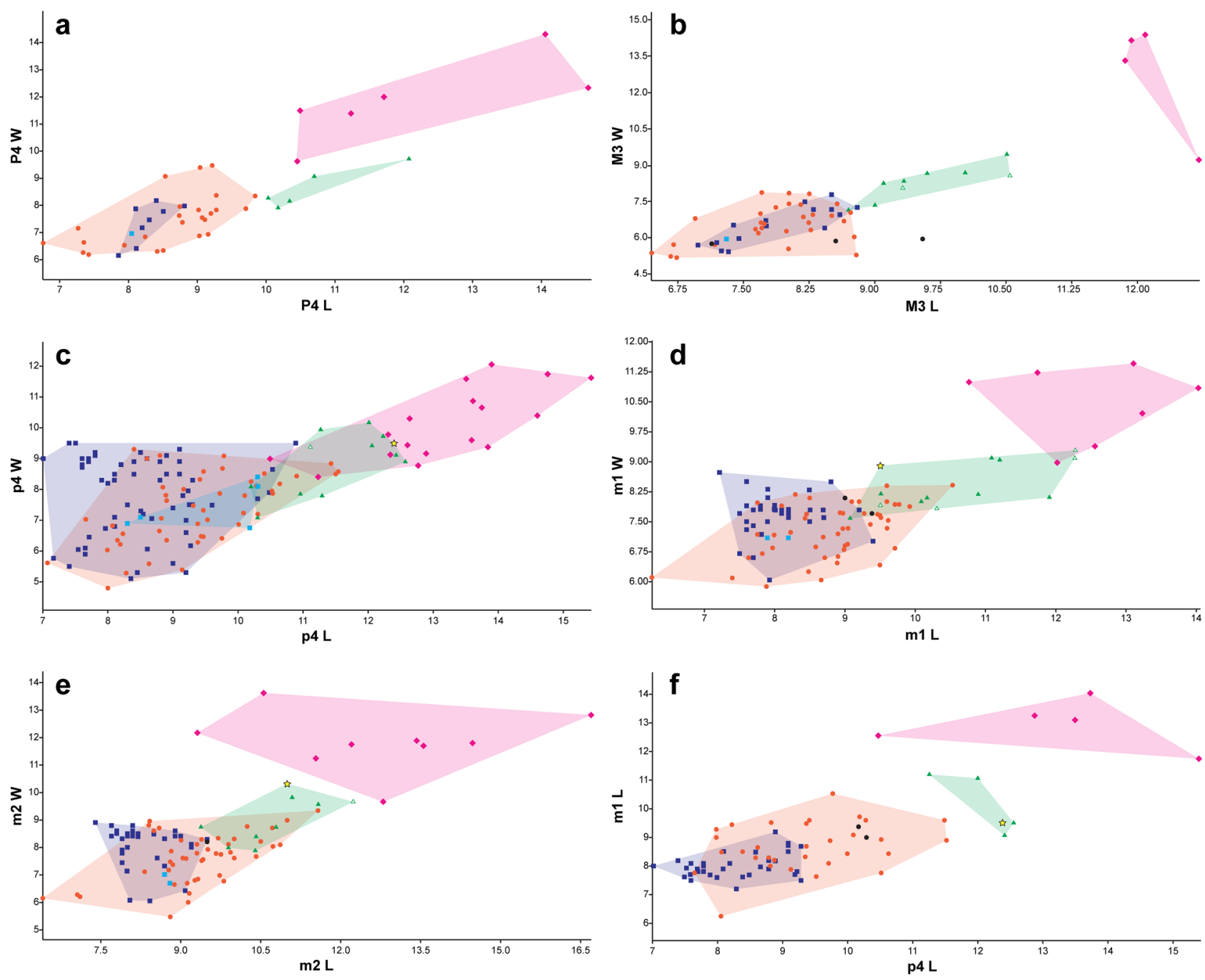

㘦 THOR15\#81

- Hystrix makapanensis $\triangle$ Hystrix cf. makapanensis

- Hystrix africaeaustralis
Hystrix cristata

Hystrix sp.
Hystrix leakeyi

Xenohystrix crassidens

Fig. 5 Biplots showing the relationships between selected dental measurements in LCOG THOR15\#81 from Olduvai Gorge and extinct and extant African Hystricinae. All raw data are reported in Online Resource 3

ESI M1815 (Fig. 4) is a left p4 similar in shape and size to ESI M1811 but, unlike this, the posterior mesostriid is less indented and no anterostriid is visible.

ESI M8282 is a fragment of a juvenile left hemimandible bearing a small fragment of $i 1$, root of dp4, almost complete $\mathrm{m} 1$, and erupting $\mathrm{m} 2$. From what can be said due to the poor state of preservation, the $\mathrm{m} 1$ appears ellipsoidal in occlusal view. What stands out in this tooth is the remarkable development of the hypoflexid, corresponding to a deep and high hypostriid on the labial wall. Occlusally, the hypoflexid is fused with the posterior mesoflexid, dividing the tooth into two similar-sized parts. Distally, the posterofossettid is particularly wide.
ESI M1812 (Fig. 4) is a left P4 with the lingual root still surrounded by a small maxillary fragment; two small labial roots are partially preserved. In occlusal view, the tooth is ellipsoidal in shape. The hypoflexus and parafossette are deep and fused each other, forming a sulcus that divides the tooth into two parts, the mesial of which includes a strong anteroloph and a well-developed paracone. No parastyle is distinguishable. The hypoflexus and parafossette correspond respectively to a deep hypostria and parastria on the lingual and labial walls, but both grooves develop only in the apical part of the crown. The anterior mesoflexus reaches the middle of the crown; the posterior mesoflexus is also deep and is fused with the short lingual mesofossette forming 
a L-shaped islet. The posterofossette is small and oval in shape. Lophs and cusps are all quite constricted, with the exception of the aforementioned large paracone.

Gondolin, GD 2 and GD A Gondolin is a Pleistocene fossil-bearing karstic system (Fig. 3). The first excavation of a series of remnant calcified in situ deposits started in early 1979 along the northern wall of the cave and later processed to yield the GD 2 faunal assemblage (ca. 1.8 Ma; Watson 1993; Adams and Conroy 2005; Adams 2006, 2012b; Herries et al. 2006; Herries and Adams, 2013). Hystrix makapanensis is the only hystricid from the Gondolin GD 2 deposits (Adams and Conroy 2005; Adams 2012b). In an initial publication on the Gondolin GD 2 fauna, Watson (1993) described a sample of 34 porcupine specimens (MNI: 4) from the deposits and attributed them to H. makapanensis. Adams (2012b) added the first description of four probable H. makapanensis teeth (MNI: 2) recovered from a test trench excavated into ex situ dumpsite (GD A; $1.95-\sim 1.78 \mathrm{Ma}$; Adams et al. 2007; Herries and Adams 2013; Adams 2018) deposits at Gondolin that yielded two isolated hominin teeth (Menter et al. 1999). The whole collection would make the GD 2 and GD A H. makapanensis sample the first with clearly associated cranial and postcranial specimens, and the first formally described occurrence of the species from a South African Plio-Pleistocene locality outside Makapansgat (Adams 2012b). Some diagnostic characteristics of the species found by Adams (2012b) agreed with those proposed by Maguire (1976). Regarding the teeth, in contrast to modern and fossil $H$. africaeaustralis specimens at a similar stage of wear, H. makapanensis from Gondolin is clearly distinguished by: (1) the larger size of the dentition (as a matter of fact, the upper teeth from Gondolin are amongst the largest for H. makapanensis; Fig. 5); (2) the greater hypsodonty; (3) the well-formed roots on the premolars and molars; (4) the presence of a strong anterior mesoflexus on the P4, also present in unworn $\mathrm{dP} 4$, which in combination with the hypoflexus, bisect the tooth into mesial and distal lobes; (5) the shape of the M3, which is wide mesially at the protocone/ paracone and narrow distally at the metacone/hypocone. In fact, character 4 is visible also in DNMNH GA7, that is, the only p4 described by Adams (2012b). Moreover, the left mandible fragment DNMNH GA839 preserves a partial p4 and most of the mandibular ramus. This mandible has an accessory mental foramen below the distal root of $\mathrm{p} 4$ and is more robust than that of $H$. africaeaustralis, thus fitting Maguire's (1976) observations on H. makapanensis. The preserved $\mathrm{p} 4$ cannot be described in detail but is certainly robust and exhibits a well-marked posterior mesostriid (Adams 2012b).

Thanks to the richness of the Gondolin sample, Adams (2012b) proposed also the first set of formal diagnostic characters for the cranium and postcranial skeleton of H. makapanensis, as compared to $H$. africaeaustralis: (1) low cranial profile (e.g., minimal frontal bone inflation); (2) robust temporal lines on the parietals that do not converge to form a sagittal crest, not even in adult individuals (on the contrary, $H$. africaeaustralis has a prominent sagittal crest developing prior to the eruption/occlusion of the M3); (3) relatively larger body size (mostly based on the nearly complete left distal humerus DNMNH G1161/G1578).

Kromdraai A Kromdraai is a Pleistocene fossil-bearing unroofed dolomite cave (Kuman and Clarke 2000; Fig. 3). It is famous because in 1938, a local schoolboy discovered several hominin teeth which were later found to belong to the holotype of Paranthropus robustus (Broom 1938). The site includes two distinct localities: Kromdraai A (KA) with a rich faunal record but lacking described hominin remains, and Kromdraai B (KB), which preserves a hominin fossil record alongside other faunal remains (Brain 1981). There has been a minimal application of dating methods to the Kromdraai site (Herries et al. 2009) but the KA deposits are most likely younger $(\sim 1.5-1.0 \mathrm{Ma})$ than those at KB (1.8-1.6 Ma) (Kuman 2007; Herries et al. 2009; Herries and Adams 2013).

Early observations by Maguire (1976) suggested that H. makapanensis might be represented at KA by a single M3 (DNMNH KA1912). The specimen is noticeably large (Fig. 5) and shows a great degree of curvature, as observed in all upper teeth of $H$. makapanensis (see character 3 of Maguire 1976 above). The dimensions at the occlusal plane are also higher than typical for $H$. africaeaustralis. There is a degree of crown 'flare', where the apex of the tooth is broader than the base, particularly mesiodistally. In wear, the tooth would have shrunk, probably as much as $1 \mathrm{~mm}$. A similar apical flare is not observable in the Gondolin specimens because they are more worn, but they do not appear to expand towards the apex. DNMNH KA1912 resembles the Makapansgat barely worn M3's (e.g., ESI M1819 and M1820) but does appear to be slightly larger.

Recent evaluation of these assemblages highlighted one additional specimen from KA (DNMNH KA1432). The finding is a partial mandible with fragmented i1, dp4, $\mathrm{m} 1$, and $\mathrm{m} 2$ freshly erupted and heading towards occlusion. The i1 (while broken and not really measurable) is narrow and the corpus lacks the robusticity observed in $H$. makapanensis specimens. The dp4 also lacks any transversal segmentation. Compared with $H$. africaeaustralis from the same site (e.g., DNMNH KA757), the corpus is similar and they only differ in the tooth dimensions (the $\mathrm{m} 1$ length and width are consistent with those of $H$. makapanensis; Fig. 5).

Based on the scantiness of material and the lack of clearcut similarities with $H$. makapanensis, the KA specimens are here referred to $H$. cf. makapanensis.

Swartkrans, Member 1 Swartkrans is an Early Pleistocene paleontological and archeological site located in the 
Cradle of Humankind World Heritage Site (Fig. 3), alongside Kromdraai, Sterkfontein, and other nearby caves. The Swartkrans hominin record comprises both P. robustus and early Homo, thus making this South African site the first to yield evidence of coeval, possibly sympatric hominin genera (Broom and Robinson 1952). The cave is divided geologically into five members. Besides hominin findings, members 1-2 (2.19-1.10 Ma; Balter et al. 2008; Herries and Adams 2013; Gibbon et al. 2014) also yielded large faunal assemblages, showing the earliest evidence of human butchery of large vertebrate carcasses in southern Africa (Pickering et al. 2008).

Porcupine remains are also found in these assemblages, although only the 2.19-1.8 Ma Member 1 Lower Bank and ca. 1.8 Ma Member 1 Hanging Remnant deposits contain a record of potentially attributable $H$. makapanensis specimens. Maguire (1976) dubitatively referred the Member 1 Hanging Remnant specimen DMP SK14237 to H. makapanensis or H. africaeaustralis, whereas de Ruiter (2003) attributed the specimen to the latter species. It is a robust left $\mathrm{p} 4$, slightly smaller than that of the complete mandible ISEM H.9 from Olduvai (described below; Fig. 5), and significantly larger than many of other specimens of fossil H. africaeaustralis from South African caves (e.g., DMP KA1432). It is roughly comparable to some of the aforementioned isolated H. makapanensis $\mathrm{p} 4 \mathrm{~s}$ from Makapansgat (ESI M1811, M1815), but it lacks a continuous transversal groove bifurcating the tooth into two lobes as in Makapansgat teeth. However, this last character might be subject of variation depending on wear.

Two associated Hanging Remnant specimens, DMP SK2466A/B, represent a robust right M3 (A) and M2 (B). The first is more worn than DMP KA1912 but is also quite large (Fig. 5) and has a similar morphology. Moreover, it had likely a 'apical flare' towards the crown apex prior to wear, similar to that observed in the Kromdraai A specimen DMP KA1912. The tooth is larger than the M3s of H. africaeaustralis from Makapansgat. DMP SK2466B perfectly fits the dimensions of the available M2s of $H$. makapanensis from various localities (Fig. 5).

DMP SKX14286 is derived from the Member 1 Lower Bank deposits and is a partial lower molar/premolar. We consider it as a p4, but it is too damaged for certain determination. The tooth is overall large, but not as much as the GD 2 specimens.

As for Kromdraai, the scarce material from Swartkrans is prudently attributed to $H$. cf. makapanensis.

Sterkfontein, Member 5 Sterkfontein is an extensive karstic system with a complex series of putatively Pliocene and Pleistocene depositional infills caves (Fig. 3) in which the first largely complete adult skull of Australopithecus africanus (aka "Mrs Ples") was discovered in 1947 (Brain 1981).
Maguire (1976) reported the dubious presence of $H$. makapanensis (DNMNH SFN15 and DNMNH SFN17) in Sterkfontein ex situ dumps. DNMNH SFN15 is a damaged right upper tooth (probably a $\mathrm{P} 4$ due to the presence of a single distal contact facet), not large enough to be fit with into H. makapanensis (taking GD 2 material as reference). DNMNH SFN17 is a right M1 or M2. It is large, but damaged around the edges so much that it is not metrically comparable. Overall, it seems smaller than the GD 2 M1/ M2s, but larger than in extant Hystrix (Fig. 5). This suggests referral of DNMNH SFN17 to $H$. cf. makapanensis.

Our reappraisal of fossils recovered from the Sterkfontein 'Extension', more formally recognized as representing Member 5 (<1.8-1.0 Ma; Herries and Shaw 2011; Pickering et al. 2019) has resulted in the identification of two more specimens, DNMNH SE1263.1 (dp4-m1) and DNMNH SE1255.1 (dp4). These specimens are probably referable respectively to the right and left mandible of the same juvenile individual. The dp4 shows an apparent (shallow) posterior mesostriid typical of $H$. makapanensis. The $\mathrm{m} 1 \mathrm{~s}$ are similar in size and morphology to ESI M8282, and are actually slightly larger than any other $\mathrm{m} 1 \mathrm{~s}$ of $H$. makapanensis, overlapping the smallest specimens of $X$. crassidens (Fig. 5). Based on these features, DNMNH SE1263.1 and DNMNH SE1255.1 are also referred to $H$. cf. makapanensis.

\section{Tanzania}

Olduvai Gorge, Bed I-FLK Frida Leakey Korongo (FLK; Fig. 3) is located in the Junction Area on the right bank of the Main Gorge. It is famous worldwide for its outstanding archeological and paleoanthropological record, including the holotypes of Paranthropus boisei (OH 5; aka Zinjanthropus or Zinj) and that of Homo habilis (OH 7), as well as several other remains of both species (Leakey 1959; Leakey et al. 1964; Day 1976; Tobias 1991). FLK was the first Olduvai site in which archeological remains were found in situ back in the 1930s and the earliest African site in which the co-occurrence of stone tools and modified bone remains appeared functionally linked (Leakey 1971; Wood 2011). Historically, the area includes three main sub-sites: FLKZinj, FLK-North (FLK-N), and FLK-North-North (FLK$\mathrm{NN}$ ), with the latter offering the densest concentrations of fossils and stone tools in the whole Gorge (Leakey 1971).

Sabatier (1978) reported one porcupine specimen from FLK-NN, 12 from FLK-N, and two from indeterminate FLK sub-sites/layers, referring all of them to " $H$. cf. makapanensis". All fossils were recovered from Bed I during Mary Leakey's 1960-1963 excavations, and are here revised in detail. A fragmented mandible (ISEM MK.23) listed by Sabatier (1978) as coming from FLK-N, is probably from site MK and is described below in a separate section as we believe it can be referred to a different species. 


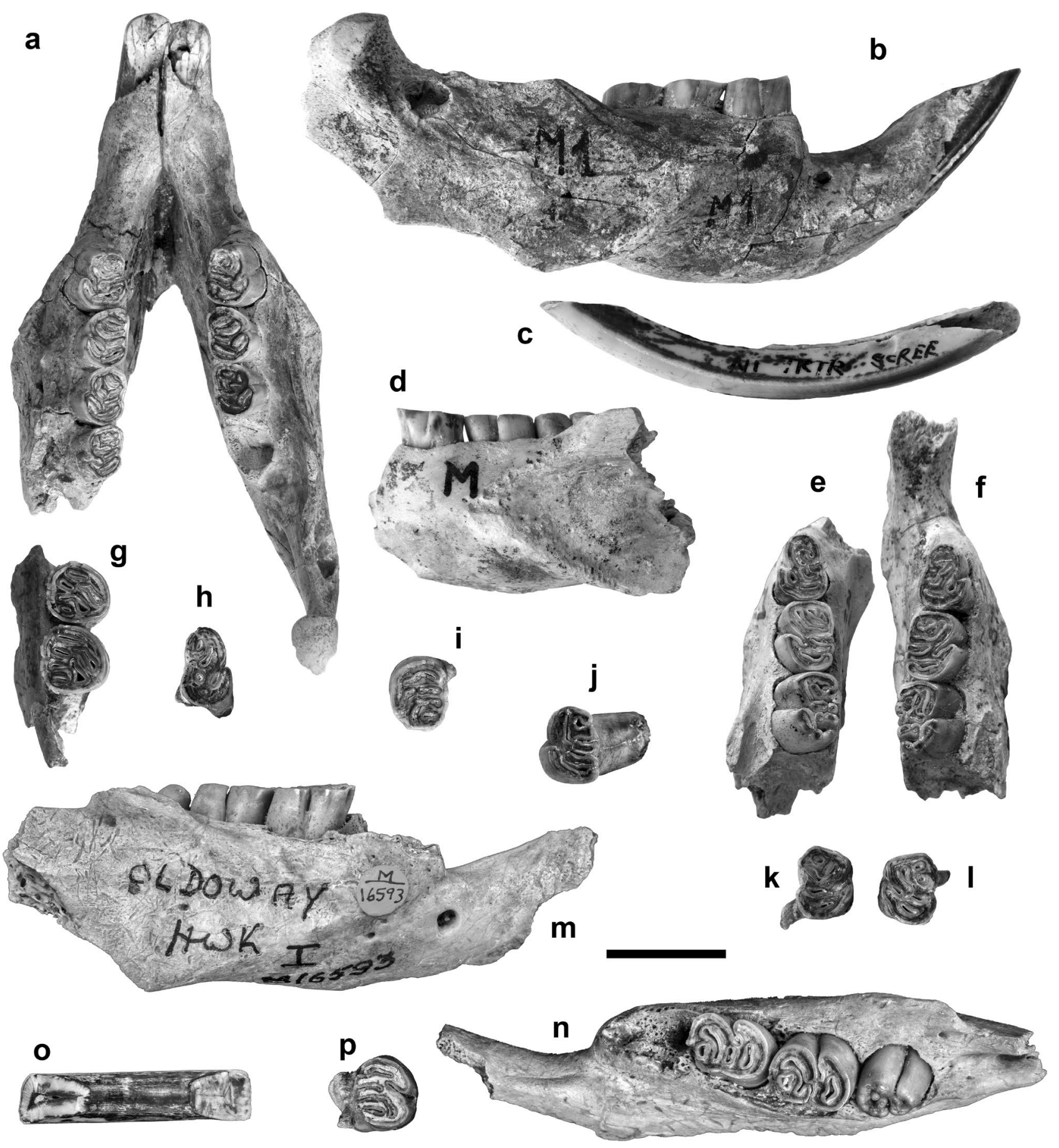

Fig. 6 Hystrix makapanensis from Olduvai Gorge (Tanzania). a-b Mandible ISEM H.9 in occlusal (a) and labial (b) views. c Left i1 ISEM n.a. in labial view. d-e Left hemimandible ISEM 6031 in labial (d) and occlusal (e) views. f Right hemimandible ISEM 874 in occlusal view. $\mathbf{g}$ Right maxillary fragment with M1-M2 ISEM H.3 in occlusal view. h Right dp4 ISEM H.1 in occlusal view. $\mathbf{i}$ Left P4 ISEM H.5 in occlusal view. j Right M2 ISEM H.6 in occlusal view. k Right dP4 ISEM H.7 in occlusal view. I ISEM H.8 left dP4 in occlusal view. m-n Right hemimandible with m1-m3 NHM M16593 in labial (m) and occlusal (n) views. o I1 fragment NHM M16595 in occlusal view. p Right M1/M2 NHM M16594 in occlusal view. The following specimens can be grouped together as belonging to the same individual: ISEM H.9+ ISEM H.3 (?); ISEM n.a. + ISEM 874+ISEM 6031; ISEM H.5+ISEM H.6 (?); ISEM H.7+ISEM H.8. Scale bar: $20 \mathrm{~mm}$ 
The most complete specimen is the mandible ISEM H.9 from layer 1 of FLK-N (see stratigraphy in Leakey 1971). It was also figured by Denys (1987). It is well preserved, as it only misses the right $\mathrm{m} 3$ and the left ramus. The specimen (Fig. 6) shows a striking resemblance to LCOG THOR15\#81 both in morphology and cheek tooth dimensions (Fig. 5). The corpus is robust and overall, the mandible appears thick and crescent-moon shaped in labial and lingual views. At the dorsal tip of the ramus, the condyle is moderately convex and with a rounded outline in dorsal view. A mental foramen is clearly visible on the right side, located quite dorsally below the mesial margin of the $\mathrm{p} 4$. In labial view, the $\mathrm{p} 4-\mathrm{m} 2$ are well visible, whereas the $\mathrm{m} 3$ is covered for most of its length by the dorsal margin of the corpus. The coronoid and angular processes are not preserved. The notch for the insertion of the masseter medialis pars infraorbitalis is located below the distal half of the p4 and is markedly concave. The posterior portion of the masseteric fossa is missing. The fossa is concave and the masseteric ridge is robust and protruding labially in occlusal view. It develops obliquely along the corpus from the ventral margin of the masseteric fossa to the limit between the $\mathrm{p} 4$ and $\mathrm{m} 1$. The lateral crest is also strong and in turn, divided into two crests separated by a groove. Posteroventrally to the symphysis, the ventral surface of the corpus forms a protruding shelf, well visible in occlusal view, which extends posteriorly up to the middle of $\mathrm{m} 1$ and hosts the long roots of the lower incisor. The diastema is shorter than the p4-m3 length and is strongly curved dorsally, forming posteriorly a steep angle with the alveolar swelling of the p4. This last part of the mandible is notably thick. The mandibular foramen is wide and clearly visible on the lingual side of the ramus, opening posteriorly to the $\mathrm{m} 3$. It is located into a deep longitudinal groove. The internal pterygoid fovea is wide and deeply concave. In occlusal view, the masseteric ridge opens outwards with a pronounced notch for the tendon of medial masseter muscle, well visible also in ventral view. In occlusal view, the four cheek teeth have almost the same width.

The i1 is robust and shows a triangular section but with rounded margins, as observed in the holotype of $H$. makapanensis ESI M1002 (Fig. 4). It emerges from the alveolus only a few millimeters.

The p4 is rectangular in labial view and trapezoidal in occlusal view, with a squared mesial margin. In occlusal view, the hypoflexid is deep and corresponds to a deep hypostriid crossing vertically the labial wall of the crown. The anterofossettid has the shape of a comma and is connected medially with the anterior mesoflexid, which in turn is connected with the labial mesofossettid. The anterior mesoflexid opens lingually, whereas the labial mesofossettid opens mesially. The posterior mesoflexid opens at about half length of the lingual margin and runs up to the midline of the tooth where it joins the hypoflexid, thus forming a V-shaped groove that divides the $\mathrm{p} 4$ into two lobes (at least on the right side). The posterior mesoflexid flows lingually into a deep posterior mesostriid, which cuts the entire lingual wall. The posterofossettid is complex and wide. The lingual part is Y-shaped, whereas the labial part is elongated mesiolabially and constricted in the middle. The anterolophulid is confined between the anterofossettid and the edge of the labial mesofossettid. The metalophulid is almost totally absent, as is the hypolophulid. The mesolophid is thick and shows a prominence on its posterolabial border. Distally, the posterolophid is squared and crosses the entire crown transversally. A large protoconid develops mesiolabially between the hypoflexid and labial mesofossettid. Mesiolingually, the metaconid is relatively small and pointed. The hypoconid is the largest cuspid. The entoconid is pointed and triangular.

The $\mathrm{m} 1$ is smaller than the $\mathrm{p} 4$ and has a more ellipsoidal occlusal outline, with a somewhat pointed mesial shape. In labial view, the posterior mesostriid is well visible and reaches the crown base like in the $\mathrm{p} 4$. In occlusal view, the hypoflexid forms a wide oval enamel islet not merged with the hypostriid on the right side, while it is open labially on the left side. No folds open on the lingual wall, but they appear as four enamel islets. Mesially, the anterofossettid is slightly inclined mesiolabially. The anterior mesoflexid is fused with the labial mesofossettid in a V-shaped islet. The posterior mesoflexid and the posterofossettid are elongated and inclined distolabially. The protoconid and metaconid are wide and rounded. The latter is more rounded than that of the $\mathrm{p} 4$. The hypoconid is narrow and constricted by the hypoflexid. The entoconid is small. The lophids are similarly developed.

The $\mathrm{m} 2$ is similar in size and morphology to the $\mathrm{m} 1$ and shows a squarish occlusal outline. Also in this tooth, the hypostriid is well visible and it reaches the base of the crown. As for the $\mathrm{m} 1$, in occlusal view, the hypoflexid is not fused with the hypostriid and no folds open on the lingual wall. The hypoflexid is elongated and inclined mesiolabially. The labial mesofossettid is well developed and runs distolingually with a middle constriction, assuming a L shape. The anterofossettid recalls that of the $\mathrm{m} 1$ but with a constriction in the middle. The anterior and posterior mesoflexids are similar to each other, elongated and inclined distolabially. The posterofossettid is long and slender like that of the $\mathrm{m} 1$. The metalophulid, mesolophid, and hypolophulid are similar to those of the $\mathrm{m} 1$, whereas all main cuspids are less developed than those of the $\mathrm{m} 1$. In particular, the hypoconid is almost absent.

The $\mathrm{m} 3$ is preserved only on the left side and is more squared than the other molars. It is overall similar to the $\mathrm{m} 2$, but with some significant differences. The hypoflexid is deep and opens labially, where it is in contact with a welldefined strong ectostylid. The anterofossettid is jagged in its mesial margin. The labial mesofossettid is well-developed 
and L-shaped. The anterior mesoflexid is small and semicircular. The posterolophid is squashed in its labial side.

The two hemimandibles ISEM 874 (right) and ISEM 6031 (left) belong to the same juvenile individual, to which the left i1 ISEM n.a. is also associated (Fig. 6). They closely resemble the mandibles described above (especially ISEM H.9 and LCOG THOR15\#81). In particular, the corpus is rather thick, with both the lateral crest and masseteric ridge strong, meeting anteriorly to form a rough bulge. This corresponds to the posterior end of the notch for the insertion of the masseter medialis pars infraorbitalis, which is positioned rather forward, under the mesial part of the $\mathrm{m} 1$. The i1 ISEM n.a. is robust and slightly curved; some fractures reveal that the dentine is particularly thick. In ISEM 874 and ISEM 6031 the dp4 is still in place. As observed in extant Hystrix species, its morphology is rather simplified with respect to the permanent premolar and, in particular, it shows a mesially pointed and more elongated occlusal shape, so that the length/width ratio is greater. The same features are observable in the isolated right dp4 ISEM H.1. As for the lower molars of ISEM 874 and ISEM 6031, the $\mathrm{m} 1$ is slightly smaller than the $\mathrm{m} 2$, and both exhibit a squarish occlusal outline. Their occlusal pattern is similar to that described for ISEM H.9, as are their dimensions (Fig. 5). In both molars, the posterior mesoflexid is connected with the hypoflexid and there is a deep centrally-positioned posterior mesostriid crossing whole labial wall of the crown.

Regarding the upper dentition, the right maxillary fragment ISEM H.3 (Fig. 6) comes from the same layer (FLK$\mathrm{N}$, layer 1) of the mandible ISEM H.9 and might belong to the same individual. ISEM H.3 preserves the M1 and M2, whose occlusal morphology and dimensions (Fig. 5) perfectly fit those of the Gondolin material (e.g., DNMNH G12143 and DNMNH G12087; Adams 2012b): the occlusal outline of both molars is almost circular (the M1 is slightly smaller than the M2); folds are rather simple in morphology; labially, the anterofossette, anterior mesoflexus, posterior mesoflexus, and posterofossette are quite small and perpendicular to the mesiodistal axis of the teeth; conversely, on the lingual side, the hypoflexus and lingual mesofossette are oriented obliquely; the latter fold is fused with the posterior mesoflexus, which corresponds on the labial wall to a deep and high posterior mesostria.

The set of teeth from FLK-N undefined layer 1-2-3 formed by ISEM H.10a-b (left and right I1), ISEM H.4 (right M1), ISEM H.5 (left P4; Fig. 6), and ISEM H.6 (right M2; Fig. 6), might also be referred to a single individual. The I1s are relatively short, markedly curved, and robust. The P4 ISEM H.5 is virtually identical to that of the maxilla DNMNH G12087 from Gondolin (Fig. 1b in Adams 2012b): the parafossette is almost as long as the entire width of the tooth; the anterior mesoflexus and posterior mesoflexus are similar sized and the latter is fused with the lingual mesofossette, forming a L-shaped islet; the posterofossette is the smallest fold but is overall well developed; the hypoflexus is oriented obliquely and touches the labial margin of the anterior mesoflexus; the hypostria is well marked on the lingual wall of the tooth. ISEM H.5 is also similar in morphology and size (Fig. 5) to ESI M1812 from Makapansgat (Fig. 4), in which, however, the parafossette and hypoflexus are fused each other. As for molars, ISEM H.4 and ISEM H.6 are similar, respectively, to the M1 and M2 of ISEM H.3 but are more rectangular in occlusal view due to less wear. In general, all permanent upper teeth from FLK show an arched profile when observed in mesial (or distal) view and (when preserved) distinct roots covered by cementum. These features are described as typical of H. makapanensis from the type locality (Maguire 1976).

ISEM H.7 and ISEM H.8 (Fig. 6) are the right and left dP4 of (presumably) the same individual. Their occlusal morphology is similar to that of the P4 ISEM H.5, including the presence of a well-developed posterior mesoflexus on the labial wall (as noted by Adams 2012b for deciduous and permanent upper premolars of $H$. makapanensis from Gondolin). ISEM H.7 and ISEM H.8 only differ from ISEM H. 5 by the more rectilinear root region, formed by three more widely spread roots.

All the above-described material from FLK-N fits the morphology of H. makapanensis from South African sites (including the type locality) and is therefore referred to this species. As a matter of fact, the FLK sample is the richest and better-preserved collection of this porcupine species in East Africa.

Olduvai Gorge, Bed I-MK In his early report on Olduvai faunal remains, Leakey (1967) mentioned the recovery of scanty porcupine remains from Bed I at sites MK and HWK (see below for this latter site). These specimens, now kept in the NHM, are described and figured here for the first time.

Maccinnes Korongo (MK; Leakey 1967), corresponding to Geolocality 11 of Hay (1976), is situated on the left bank of the eastern part of the Gorge (Fig. 3). Two porcupine teeth -right M1 or M2 NHM M16594 and I1 fragment NHM M16595 (Fig. 6) - are part of the historical NHM collections. Differently from what Dr. A.T. Hopwood hypothesized in a preliminary note (Leakey et al. 1951), Leakey (1967) already found that the teeth are too large to belong to an extant species ("Hystrix galeata" $=H$. cristata), but the material "seems to be comparable to the giant porcupine of the Australopithecine deposits in the Transvaal, which has been described by Mrs Marjorie Greenwood (1955)" (Leakey 1967: 8). In fact, Leakey did not specify whether he referred to X. crassidens or H. makapanensis, but we confidently refer the two fossils to the latter species, in light of the evident morphological and dimensional (Fig. 5) similarities with the homologous teeth described above from Gondolin 
(e.g., DNMNH G12143 and G12087) and Olduvai FLK-N (e.g., ISEM H.3 and H.10a-b).

Olduvai Gorge, Bed I-HWK A partial right hemimandible with m1-m3 (NHM M16593; Fig. 6) was collected during L.S.B. Leakey's early expeditions at Olduvai and is currently part of NHM historical collections. The fossil comes from Bed I of site HWK (Fig. 3), i.e., the same site of LCOG THOR81\#15. However, it is likely that NHM M16593 was collected in the eastern part of the site, where the initial survey efforts were focused. The specimen was mentioned by Leakey (1967), who confirmed Hopwood's idea that it may be referred to a living African porcupine species (H. cristata). We disagree with Leakey's taxonomic opinion as we find several similarities between NHM M16593 and the mandibles and lower teeth of H. makapanensis described above: the corpus is robust; in labial view, the $\mathrm{m} 1$ and $\mathrm{m} 2$ are well visible, while $\mathrm{m} 3$ is almost totally covered by the dorsal margin of the corpus; the masseteric ridge is straight, strong, and runs obliquely from the ventral margin of the masseteric fossa upward through the corpus, meeting the lateral crest to form a visible notch for the insertion of the masseter medialis pars infraorbitalis, which is placed below the distal half of the p4; the mandibular diastema is robust and less curved than in Olduvai specimens (e.g., LCOG THOR15\#81, ISEM H.9) but similar to the holotype ESI M1002 (Fig. 4); in occlusal view, both the lateral crest and symphysis area are shelf like; a wide mental foramen is clearly visible below the $\mathrm{p} 4$ mesial edge, whereas an accessory foramen is placed below the distal half of the p4, as reported in Maguire's (1976) diagnosis of $H$. makapanensis; three mandibular foramina are visible on the lingual side, and two of them are located into a deep groove (as in ISEM H.9); the occlusal morphology of the $\mathrm{m} 1$ and $\mathrm{m} 2$ are virtually identical to that described for ISEM 874 and ISEM 6031 from FLK (Fig. 6), which probably belonged to a slightly younger individual (based on the less advanced wear of the $\mathrm{m} 2$ ); the $\mathrm{m} 3$ is freshly erupted so it is difficult to compare it with the other fossils from Olduvai. The length and width of the $\mathrm{m} 1$ and $\mathrm{m} 2$ fall in the ranges of H. makapanensis (Fig. 5). In the light of these characters, the mandible NHM M16593 can be confidently attributed to $H$. makapanensis.

Note on the Occurrence of Two Other Porcupine Species in Olduvai The taxonomy of four specimens from the FLK area referred to $H$. cf. makapanensis by Sabatier (1978), is here revised due to clear morphological differences with the above-described material of this species. The left hemimandible with i1-m2 ISEM 159 (Online Resource 4) and the right $\mathrm{m} 2$ ISEM 31 from FLK-N layer 5 might belong to the same juvenile individual. Although fragmented, the corpus appears slightly slenderer than in ISEM 6031 from FLK-N layer 1-2-3, i.e., similar-aged individual of $H$. makapanensis. The i1 of ISEM 159 is also less robust than that (ISEM n.a.) associated with the same hemimandible. The dp4 is overall similar to ISEM 6031, ISEM 874, and ISEM H.1 but shows a more squarish occlusal outline and a more complex wear pattern, with the hypoflexid fused with the posterofossettid and all other main folds connected is a sort of E-shaped islet; no vertical grooves are clearly visible on the labial and lingual walls. The same can be said for the $\mathrm{m} 1$, which differs from the homologous teeth from FLK-N layer 1-2-3. In particular, this tooth exhibits a clear constriction of the distal extremity and, mesially, a complex islet with jagged edges formed by the confluence of the anterofossettid, labial mesofossettid, and anterior mesoflexid. Mesially, there is a wide and deep contact facet for the dp4. The $\mathrm{m} 2$-both the left one in ISEM 159 and the isolated right one ISEM $31-$ is freshly erupted, but seems to show the same general morphology of the $\mathrm{m} 1$ (except for the absence of any mesial contact facet).

The same morphology characterizes the isolated right $\mathrm{m} 1$ ISEM 30 (Online Resource 4), which also shows a sharp constriction of the distal lobe, a long sub-vertical hypoflexid fused with the posterofossettid, and an evident mesial contact facet for the dp4. Moreover, in this molar, due to the more advanced wear, the anterofossettid and anterior mesoflexid join in a wide islet oriented mesiodistally, in the middle of which a small enamel circle develops.

Similar features can be observed in the right mandibular fragment ISEM 40 (Online Resource 4) from FLK-NN layer 1 , which preserves a freshly erupted $\mathrm{p} 4$ without the continuous posterior mesostriid on the lingual wall typical of $H$. makapanensis. The $\mathrm{m} 1$ and $\mathrm{m} 2$ are similar to those described above (ISEM 159 and ISEM 30). The latter tooth exhibits a particularly convoluted wear pattern, with the hypoflexid, posterior mesoflexid, and posterofossettid converging in a Y-shaped groove with undulated margins.

All the above characters, combined with the slightly lower dimensions of these fossils (Online Resource 3), contradict an attribution to $H$. makapanensis. Indeed, the observed morphologies find correspondence in some specimens of extant $H$. africaeaustralis that we examined. Given the scantiness of material, we prefer here a preliminary attribution of ISEM 159, ISEM 30, ISEM 31, and ISEM 40 to $H$. cf. africaeaustralis. It is worth noting that these four specimens come from older layers than those referred to $H$. makapanensis (or at least, those with defined stratigraphic provenance). In particular, while H. makapanensis material seems concentrated in uppermost Bed I (several fossils from FLK-N layers 1-3; ca. 1.8 Ma; Stanistreet et al. 2020) and lowermost Bed II (LCOG THOR15\#81 from HWK$\mathrm{W}$; ca. $1.8-1.7 \mathrm{Ma}$ ), the remains of $H$. cf. africaeaustralis come from an earlier portion of upper Bed I (ISEM 31 from FLK-N layer 5, i.e., lower than layers 1-3; see stratigraphic sections in Leakey 1971) or even from middle Bed I (ISEM 40 from FLK-NN layer 1; ca. 1.84 Ma; Stanistreet et al. 
2020), thus making them the earliest porcupine remains from Olduvai Gorge.

Particularly noteworthy is another specimen attributed to $H$. cf. makapanensis by Sabatier (1978), namely the right hemimandible with m3 ISEM MK.23 (Online Resource 4). Reported as discovered at FLK-N (Sabatier 1978), we believe that it is in fact from site MK in light of: (1) the original label that we found associated to the fossil at ISEM ("Oldoway 1959 MK”, i.e., earlier than Mary Leakey's 1960-1963 excavations); and (2) the taphonomic appearance totally different than that of the H. makapanensis material from FLK-N. The hemimandible shows some clear differences from those that we refer to the latter species: the anterior part of the masseteric ridge is sub-vertical (instead of being more oblique) and meets a marked lateral crest below the m1-m 2 contact (i.e., more posteriorly than in $H$. makapanensis); the diastema is incomplete, but is seems quite short; the $\mathrm{m} 3$ is particularly small compared to the size of the mandible; in occlusal view, it shows a simple wear pattern, with no folds opening on the labial and lingual sides; the crown is covered by a thick cementum layer; the other teeth are not preserved, but based on the alveolar morphology, they must have been large and with short but individualized roots. These features fit the morphology of $X$. crassidens described in the literature (Greenwood 1955; Maguire 1976) and directly observed in some specimens that we analyzed (e.g., ESI M1008 and ESI M1802 from Makapansgat; NME A.L.133-8 from Hadar). In light of the fragmentary nature of specimen ISEM MK.23, we cautiously refer it to cf. $X$. crassidens.

Laetoli, Upper Laetolil Beds and Upper Ndolanya Beds Laetoli (northern Tanzania; Fig. 3) is one of the most important paleoanthropological sites in the world thanks to some key discoveries for the understanding of human evolution. Among these, the holotype and other remains of Australopithecus afarensis (Leakey et al. 1976; Johanson et al. 1978) and the earliest bipedal footprints in the world (ca. $3.66 \mathrm{Ma}$ ) attributed to the same species (Leakey and Hay 1979; Leakey and Harris 1987; Masao et al. 2016) stand out.

Denys $(1987,2011)$ reported the occurrence of three porcupine species from the Upper Laetolil Beds and Upper Ndolanya Beds (3.85-3.63 Ma and ca. 2.66 Ma, respectively; Deino 2011): the new species H. leakeyi from Localities $2-12,15$, and 20 , including all the material initially described by Sabatier (1978) as H. aff. cristata; H. makapanensis from Localities 3, 5, 6, 8, 10, 15, and 18; and $X$. crassidens from Localities 1, 2, 10, and 15. Few specimens were recovered during Mary Leakey's 1974-1979 expeditions in Laetoli (LAET series number), whereas several others were collected during the Eyasi Plateau-Laetoli Paleontological Expeditions in 2000-2005 (EP series number). In this section, we re-examine all this material, to which are added some unpublished EP specimens recovered in more recent years (see Table 1 for all details).

One of the best-preserved remains is the left hemimandible with p4-m2 NMT EP988/00 (Fig. 7) from the Upper Ndolanya Beds (Loc. 18). The first tooth was interpreted as a dp4 by Denys (2011), but based on its morphology and wear stage (also in comparison with that of other teeth), we think the tooth is permanent. The robust corpus is broken ventrally and posteriorly and the ramus is missing. Labially, a wide mental foramen is visible below the mesial half of the $\mathrm{p} 4$. The notch for the insertion of the masseter medialis pars infraorbitalis is visible and wide. The mandibular diastema is markedly curved. In occlusal view, the preserved teeth have almost the same size. The p4 is squared mesially, wider distally, and shows a posterior mesostriid that crosses the lingual wall from the top to bottom. On the labial side, the hypostriid is also deep and high.

The left hemimandible with p4-m3 NMT EP255/19 (Fig. 7) also from the Upper Ndolanya Beds (Loc. 15) -although fragmented, quite weathered, and belonging to an adult individual with very worn teeth- shows the same general features, especially in the morphology of the $\mathrm{p} 4$. The same goes for the left hemimandible fragment with p4-m2 NMT EP655/05 (Fig. 7), firstly attributed to $H$. leakeyi (Denys 2011). In our opinion, the morphology and size of this specimen perfectly fit those observed in the above-described mandibular remains. Consistent characters are also found in the isolated right p4 NMT EP2015/00 (Fig. 7), which furthermore shows a strong overall similarity with ESI M1811 (Fig. 4) from Makapansgat, referred to $H$. makapanensis.

As for the upper dentition, the most significant specimen is NMT EP329/00 (Fig. 7), which consists of the left $\mathrm{P} 4-\mathrm{M} 2$ and right P4-M1 of the same individual (previously identified as "six associated molars of H. makapanensis"; Denys 2011). The morphology of these teeth is virtually identical to that of DNMNH G12143, DNMNH GA11, and DNMNH GA50 from Gondolin referred to H. makapanensis (Adams 2012b). The same goes for the isolated M1/M2 NMT EP086/03 and NMT EP1070/16 (Fig. 7). Also, the M3s NMT LAET74-256, NMT LAET75-1971(R1), NMT EP1996/00, NMT EP3354/00 (Fig. 7) fit the morphology described for the homologous teeth from Gondolin, especially in the strong distal narrowing (Adams 2012b).

The 11 fossils reported above represent a sample confidently referable to $H$. makapanensis, as also confirmed by their dental dimensions (Fig. 5). On the contrary, some specimens previously attributed to the same species do not show characters consistent with such identification. In particular, the right p4 NMT LAET75-1971(R2) (referred to H. makapanensis by Sabatier 1978 and H. cf. makapanensis by Denys 1987) does not show a well-developed posterior mesostriid, has a quite rounded occlusal outline, and is particularly large 

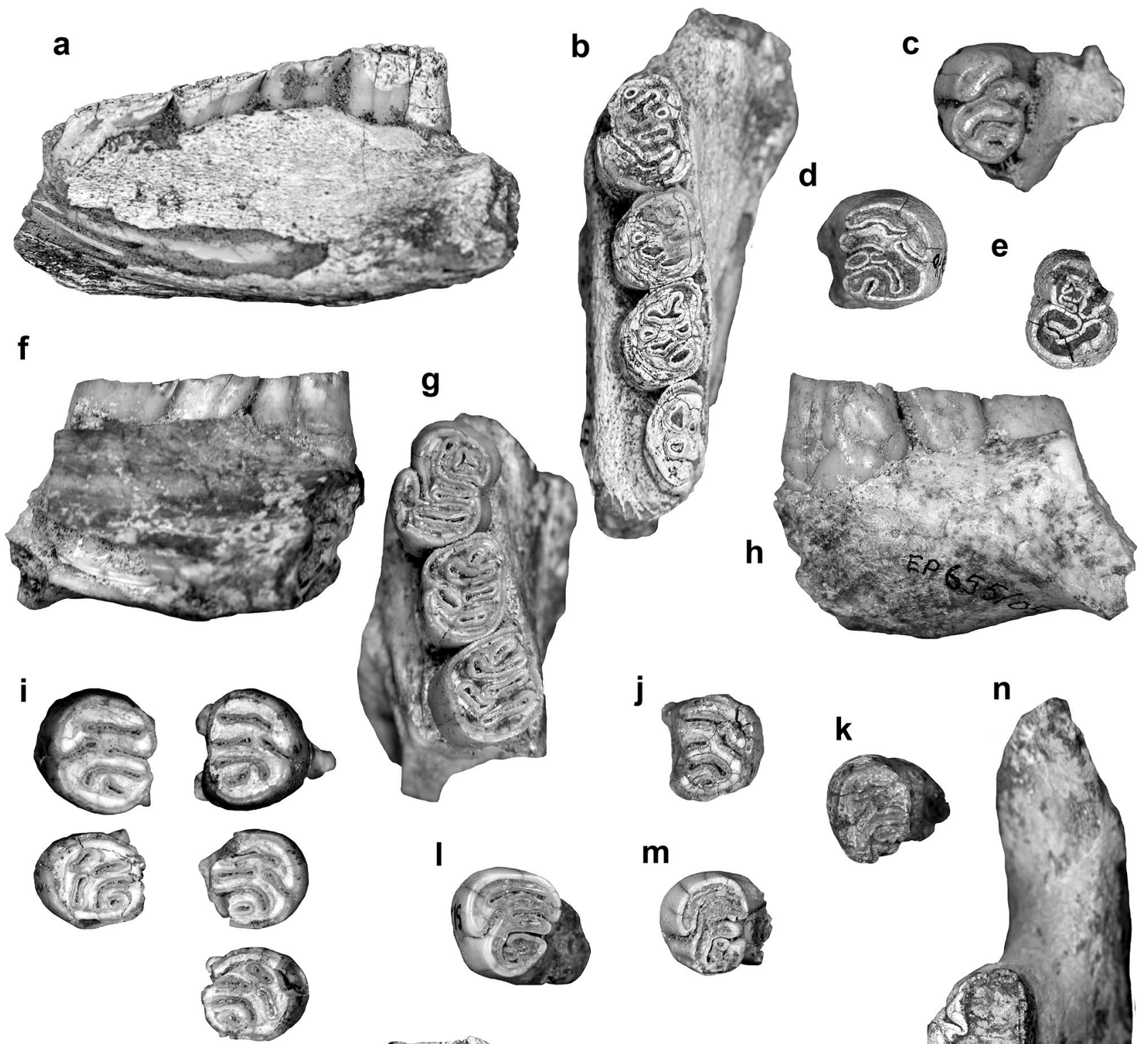

m
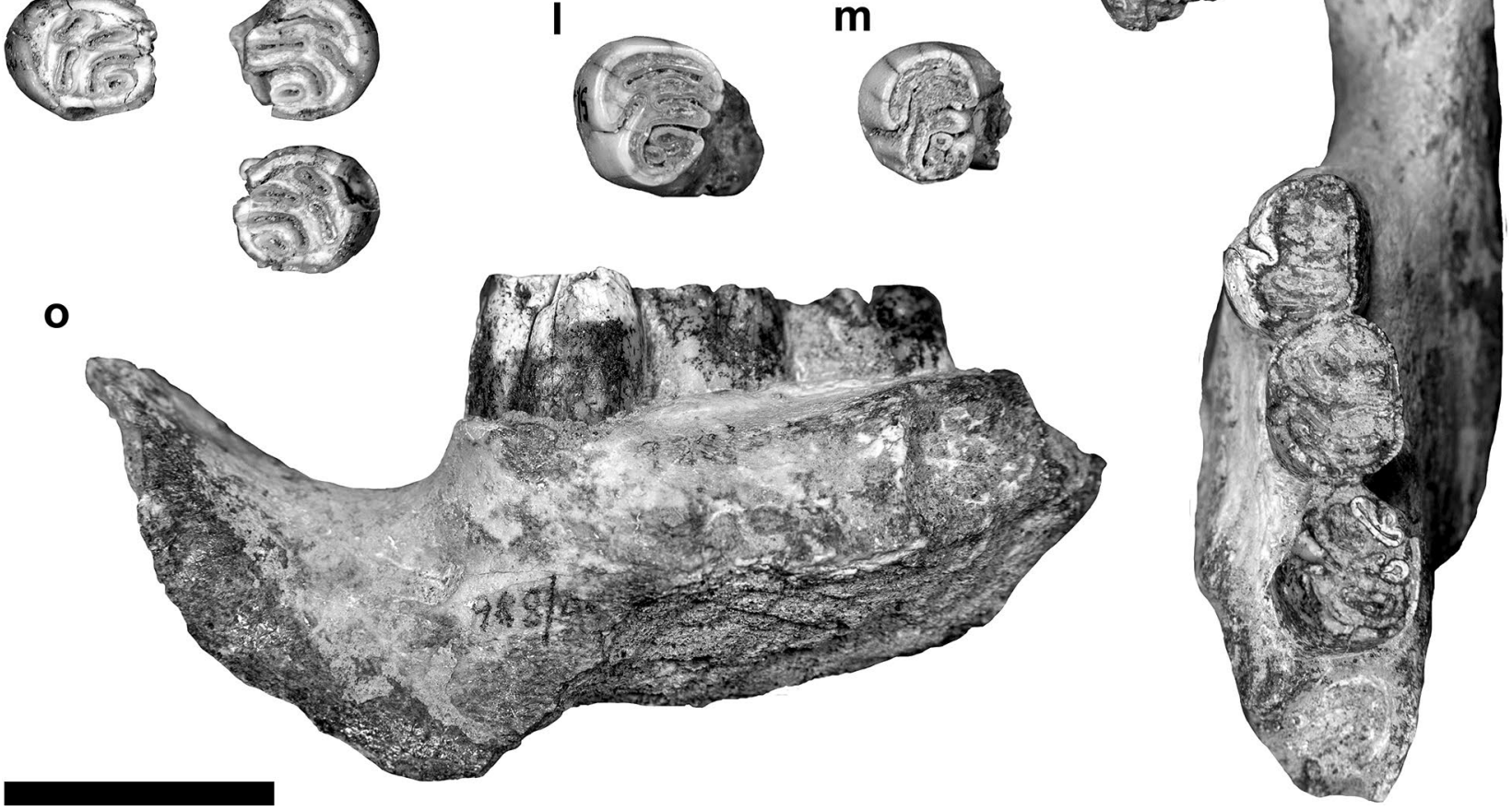
4Fig.7 Hystrix makapanensis from Laetoli (Tanzania). a-b Left hemimandible with fragmented i1, p4-m2 and fragmented m3 NMT EP255/19 in lingual (a) and occlusal (b) view. c Left M3 NMT LAET74-256 in occlusal view. d Right M1/M2 NMT EP1070/16 in occlusal view. e Right p4 NMT EP2015/00 in occlusal view. f-h Left hemimandible with p4-m2 NMT EP655/05 in lingual (f), occlusal (g), and labial (h) views. i Left P4-M2 and right P4-M1 NMT EP329/00 in occlusal view (same individual). j Right M3 NMT EP1996/00 in occlusal view. $\mathbf{k}$ Left M1/M2 NMT EP086/03 in occlusal view. 1 Left M3 NMT LAET75-1971(R1) in occlusal view. m Left M3 NMT EP3354/00 in occlusal view. n-o Left hemimandible with p4-m2 NMT EP988/00 in occlusal (n) and labial (o) views. Scale bar equals $20 \mathrm{~mm}$

(Online Resource 4), all characters supporting an attribution to $X$. crassidens. Instead, the left M3 NMT EP376/05 ("broken molar" of $H$. makapanensis according to Denys 2011) is too damaged and little worn for a determination at species rank.

\section{Kenya}

Chemeron Formation The Chemeron Fm. (5.6-1.6 Ma; Deino and Hill 2002) is part of the extensive fossiliferous sedimentary sequence of the Tugen Hills (Baringo District, western Kenya; Fig. 3). The unpublished specimen NMK BC432 from an undefined Chemeron locality/layer is a porcupine left hemimandible with p4 (Fig. 8). The corpus is quite elongated in labial view and thick in occlusal view. The mandibular diastema is incomplete but appears moderately curved. Labially, the anterior part of the masseteric ridge is preserved; it is prominent and oblique, ending anteriorly below the $\mathrm{p} 4$ distal half. The long and robust i1 is still in place, but its tip is broken where the whole corpus lacks its anterior portion. The $\mathrm{p} 4$ is large and trapezoidal in shape, resembling NMT EP655/05 in morphology and size (Fig. 5). The hypostriid and posterior mesostriid cross vertically the whole labial and lingual walls, respectively. All these characters allow referral of NMK BC432 to H. makapanensis, which therefore is the only specimen of this species reported in Kenya so far (unfortunately from an unknown Chemeron stratigraphic horizon).

\section{Ethiopia}

Shungura Formation, Member G The Lower Omo Valley in the northern Turkana Basin (southern Ethiopia; Fig. 3) is known for its outstanding Plio-Pleistocene paleontological and archeological records (Boisserie et al. 2008 and references therein). Among the sedimentary deposits of the Omo Group, one of the major geological formations is the 766 m-thick Shungura Fm., divided into 12 members spanning the interval 3.6-1.16 Ma (Feibel et al. 1989; Alemseged 2003). The porcupine material analyzed herein comes from Member G (ca. 2.33-1.9 Ma; Alemseged 2003).
The upper molars (M1 or M2) NME L65-35, ISEM L628228, and ISEM OMO243-4838 (Fig. 8) can be confidently referred to H. makapanensis in light of their size (Fig. 5) and morphology (see, for example, the circular occlusal outline, the parafossette and anterior mesoflexus opening labially, the lingual mesofossette and posterior mesoflexus merging in a L-shaped islet, the rounded posterofossette is round in shape; all characters already described in NMT EP329/00 from Laetoli and DNMNH G12087 and DNMNH GA11
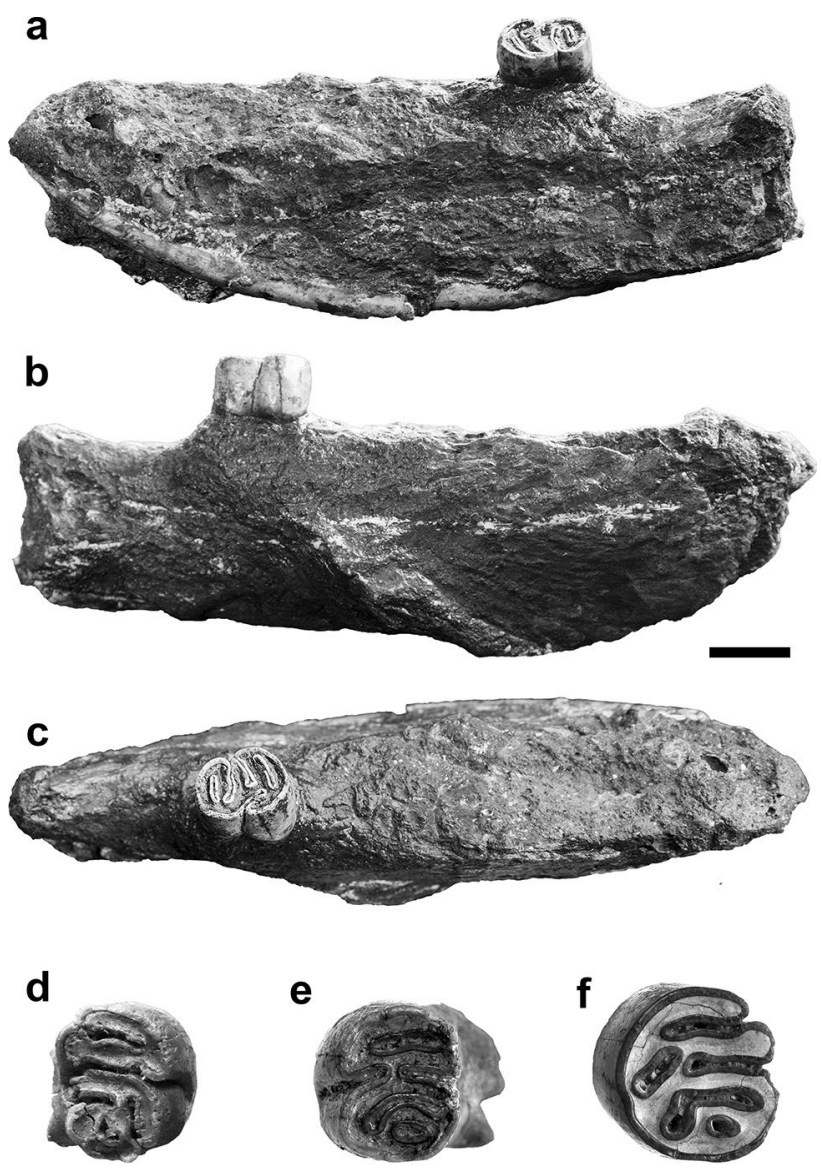

g
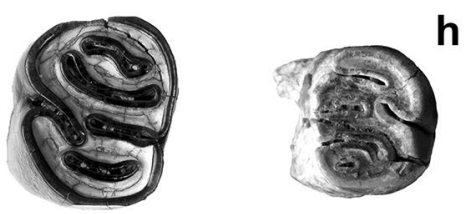

h

Fig. 8 Hystrix makapanensis from Kenya and Ethiopia. a-c Left hemimandible with p4 NMK BC432 in lingual (a), labial (b), and occlusal (c) views from Kenya (Chemeron Formation, undefined stratigraphic horizon). d Right M1/M2 NME L65-35 in occlusal view from Ethiopia (Shungura Formation, Member G). e Left M1/ M2 ISEM OMO243-4838 in occlusal view from Ethiopia (Shungura Formation, Member G). f Left M1/M2 ISEM L628-228 in occlusal view from Ethiopia (Shungura Formation, Member G). g Left m1/m2 ISEM L627-154 from Ethiopia (Shungura Formation, Member G). h Left m1 NME A.L.265-9 in occlusal view from Ethiopia (Hadar Formation, Submember SH-2). Scale bars equal $10 \mathrm{~mm}$ 
from Gondolin, among others). In agreement with Sabatier (1978), we refer to $H$. makapanensis also the left $\mathrm{m} 1 / \mathrm{m} 2$ ISEM L627-154 (Fig. 8).

On the other hand, some specimens attributed to $H$. cf. makapanensis by Sabatier (1978) — namely the right $\mathrm{m} 1 /$ m2 ISEM L32-210 (right M1/M2 in Sabatier 1978), the left p4 ISEM L51-10a, the indeterminate left upper tooth ISEM L382-5 (right P4 in Sabatier 1978), and the left p4 ISEM OMO18-552 (Online Resource 4)—should be reassigned to $X$. crassidens (see dimensions in Fig. 5 and Online Resource 3).

Hadar, Submember SH-2 The Pliocene site of Hadar (northeastern Ethiopia; Fig. 3) is known worldwide for its paleontological heritage, in particular for the record of $A u$. afarensis, including the famous skeleton of "Lucy", among others (Johanson and Taieb 1976; Johanson et al. 1978, 1982; Kimbel et al. 2004). The Submember SH-2 (hosting the Kada Me'e Tuff dated at ca. 3.36 Ma) is one of the four in which the Sidi Hakoma Member of the Hadar Formation is divided (Campisano and Feibel 2008). A single porcupine specimen from SH-2, the left m1 NME A.L.265-9 (Fig. 8), shows morphology and size (Fig. 5) compatible with $H$. makapanensis, resembling the homologous tooth from other localities (e.g., LCOG THOR15\#81 and ISEM H.9 from Olduvai). However, pending new discoveries from Hadar, the tooth is here referred to $H$. cf. makapanensis.

\section{Body Size Estimation}

Using the $\mathrm{m} 1$ length as a proxy (see Material and Methods), we estimated for the considered species the body masses

Table 2 Estimations of body mass (BM) based on m1 length (m1L) in extant and extinct African Hystricinae. Sample size is in parentheses following the species name. Mean body mass for each species is in bold

\begin{tabular}{lllr}
\hline & & $\mathrm{m} 1 \mathrm{~L}(\mathrm{~mm})$ & $\mathrm{BM}(\mathrm{kg})$ \\
\hline Hystrix cristata (35) & $\min$ & 7.21 & 8.39 \\
& $\operatorname{mean}$ & 7.21 & $\mathbf{8 . 3 9}$ \\
& $\max$ & 9.40 & 18.11 \\
Hystrix africaeaustralis (48) & $\min$ & 7.40 & 9.05 \\
& $\operatorname{mean}$ & 8.85 & $\mathbf{1 5 . 1 9}$ \\
& $\max$ & 10.53 & 25.18 \\
Hystrix leakeyi (2) & $\min$ & 7.90 & 10.94 \\
& $\operatorname{mean}$ & 8.05 & $\mathbf{1 1 . 5 5}$ \\
Hystrix makapanensis (13) & $\max$ & 8.20 & 12.19 \\
& $\min$ & 9.08 & 16.38 \\
& $\operatorname{mean}$ & 10.60 & $\mathbf{2 5 . 6 8}$ \\
Xenohystrix crassidens $(7)$ & $\max$ & 12.28 & 39.34 \\
& $\min$ & 10.77 & 26.88 \\
& $\operatorname{mean}$ & 12.50 & $\mathbf{4 1 . 3 8}$ \\
& $\max$ & 14.04 & 58.03 \\
\hline
\end{tabular}

reported in Table 2. Estimates for extant species (mean values of about 11.5 and $15 \mathrm{~kg}$ for $H$. cristata and $H$. africaeaustralis, respectively) are close to actual values reported in the literature (H. cristata: Mori and Lovari 2014; Kingdon 2015; H. africaeaustralis: Smithers 1983; Corbet 1991; Barthelmess 2006). The estimated body mass for H. leakeyi is virtually identical - though based on two specimens only - to that of $H$. cristata. On the other hand, H. makapanensis, with an estimated average body mass of about $25.7 \mathrm{~kg}$, was more than two thirds heavier than extant $H$. africaeaustralis. The giant-sized porcupine $X$. crassidens was even larger, with average estimation of about $41 \mathrm{~kg}$ (Table 2), i.e., more than twice as heavy as the extant African Hystrix species and close to average values of the extant capybara Hydrochoerus hydrochaeris (Ferraz et al. 2005), which is the largest living rodent.

\section{Discussion}

The discovery of the mandible LCOG THOR15\#81 from Olduvai HWK-W prompted the review of the entire African record of $H$. makapanensis, an extinct species that has been the subject of few detailed systematic studies in the past. This review focused on comparing the fossils of H. makapanensis (some hitherto unpublished) and other extinct and extant African Hystricinae from the Miocene to the present. Comparisons based solely on morphological characters of the cheek teeth confirmed that this approach should be followed with caution in the study of porcupines, because the occlusal pattern shows a very strong intraspecific and even intraindividual variability (van Weers 2003, 2005; van Weers and Rook 2003). In fact, it is influenced by wear (therefore by age) and can even result in different morphologies between the right and left teeth of the same individual. Nevertheless, also thanks to the richness of the analyzed samples, we were able to identify some consistent dental characters that allow a clear definition of $H$. makapanensis, improving the efforts made by Greenwood (1955), Maguire (1976), and Adams (2012b). Alongside these characters of the cheek teeth, the emended diagnosis (reported in the appropriate section above) was enriched by cranial characters defined by Adams (2012b) and by previously unpublished characters on the morphology of the mandible and lower incisor (Fig. 9).

By superimposing morphological data with biometric data, the picture becomes clearer. We compared the length and width of upper and lower cheek teeth of H. makapanensis with those of other species (Fig. 5). For each tooth examined, we confirm that the dental dimensions of $H$. makapanensis are about one third larger than those of other African Hystrix, i.e., H. cristata, $H$. africaeaustralis, and $H$. leakeyi. These latter species form a homogeneous set, in which it is difficult to recognize significant interspecific differences, if 

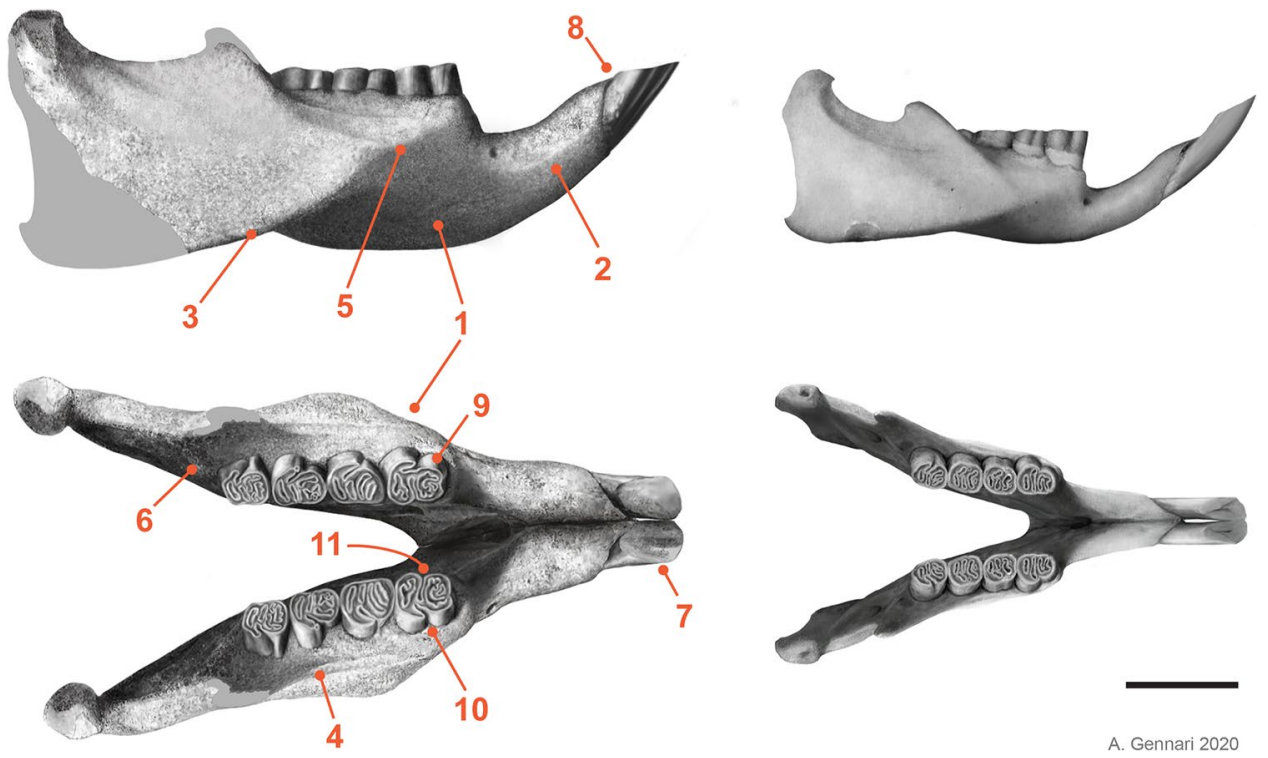

A. Gennari 2020

Fig. 9 Morphological comparison between the mandible of Hystrix makapanensis (left) and that of extant Hystrix africaeaustralis (right), depicted to scale in labial (top) and occlusal (bottom) views. The mandible and lower teeth of $H$. makapanensis are based on the bestpreserved fossil specimens available (e.g., LCOG THOR15\#81 and ISEM H.9); reconstructed portions (i.e., those missing in all fossils) are in solid gray. Significant morphological characters of H. makapanensis are indicated: 1 , massive mandibular corpus; 2, robust diastema; 3, oblique masseteric ridge ending below the p4-m1 contact; 4 , shelf-like lateral crest; 5 , masseteric ridge and lateral crest meet-

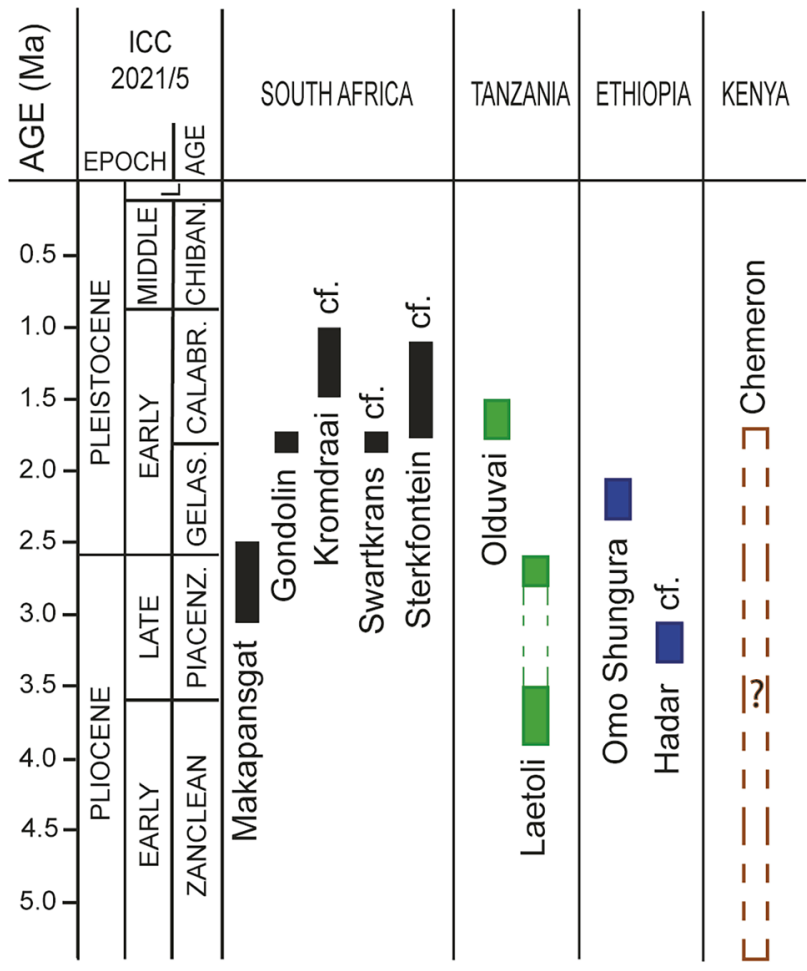

Fig. 10 Summary of the geographical and chronological distribution of Hystrix makapanensis in Africa. References for the date ranges are in the main text. The stratigraphic provenance of the only known specimen from the Chemeron Formation (Kenya) is unknown. Abbreviations: ICC, International Chronostratigraphic Chart; L, Late ing anteriorly to form a strong notch for the insertion of the masseter medialis pars infraorbitalis; 6 , wide mandibular foramen placed within a longitudinal groove; 7, i1 robust and sub-triangular in section, with rounded edges; 8, i1 emerging little from the alveolus; 9, p4 is the largest lower cheek tooth, it has a trapezoidal occlusal outline and deep hypoflexid and posterior mesoflexid; 10, deep and high hypostriid; 11, deep and high posterior mesostriid. See our emended diagnosis of $H$. makapanensis for more details. Scale bar equals $30 \mathrm{~mm}$. Artwork by Alberto Gennari

not a slightly larger overall size of $H$. africaeaustralis. Some African fossil teeth referred to Hystrix sp. also fall into this set (Fig. 5). However, these dimensional differences between African species become more subtle when large samples are examined, i.e., ranges tend to overlap more (see, for instance, the biplot on the p4; Fig. 5). At least for the lower teeth, this problem is overcome if we compare the same variable for different teeth, for example the length of $\mathrm{m} 1$ versus that of p4 (Fig. 5). In this case, although with smaller samples (due to the need to compare the $\mathrm{p} 4$ and $\mathrm{m} 1$ from the same individual), the separation between the various species is much clearer, with $H$. makapanensis falling between (but not overlapping with) $H$. cristata/africaeaustralis and $X$. crassidens. These differences in tooth size undoubtedly correspond to significant differences in body size (Table 2).

No information on the ecology of extinct African porcupines is available. Brachydonty of $X$. crassidens might indicate that this form fed on softer plant sources in forested environments (Maguire 1978). Conversely, the marked hypsodonty of $H$. makapanensis might be suggestive of adaptation to arid or semi-arid environments, as in extant species (Happold 2013). More studies are needed to investigate these aspects, which are made even more intriguing by the fact that in some cases multiple porcupine species have been found in the same paleontological locality. As for South African caves, 
H. makapanensis seems to co-occur with $H$. africaeaustralis in Swartkrans Member 1, Sterkfontein Member 5, and Kromdraai A and with $H$. africaeaustralis and $X$. crassidens in Makapansgat members 3-4 (Greenwood 1955; Maguire 1976; Adams 2012b). On the contrary, in Olduvai Gorge, $H$. cf. africaeaustralis is here recognized for the first time from earlier layers than those yielding $H$. makapanensis, while little can be said on cf. $X$. crassidens, which is represented to date only by a single specimen (ISEM MK.23) from an unknown stratigraphic layer. If confirmed, regardless of its stratigraphic provenance, this would represent the last occurrence of $X$. crassidens, which has never been reported beyond the Pliocene-Pleistocene transition (Denys 2011). In Laetoli, the situation seems similar to Makapansgat, with the co-occurrence of at least three species (H. makapanensis, $H$. leakeyi, and $X$. crassidens) or even four (see specimens here referred to Hystrix sp.) at least in some stratigraphic intervals (Online Resource 3). Finally, in Omo Shungura, $X$. crassidens is limited to earlier stratigraphic members (B-C) than $H$. makapanensis $(\mathrm{G})$, which instead co-occurs with $H$. cristata (Online Resource 3).

Our reappraisal of the entire record of $H$. makapanensis confirms the validity of this species, which is recognizable from other extinct and extant African Hystricinae, especially when large samples and well-preserved craniodental remains (mandibles and lower teeth above all) are available. The new diagnosis provided herein offers the most detailed tool for taxonomic recognition of $H$. makapanensis. Its geographical distribution extended along the southeastern belt of Africa, from Ethiopia to South Africa, although its possible presence in the southwestern part of the continent cannot be verified due to the absence of paleontological sites. Thus, the distribution of $H$. makapanensis seems roughly to overlap that of $H$. africaeaustralis, even if the range of the latter has its northeastern limit in Tanzania and southwestern Kenya (i.e., it does not extend towards the Horn of Africa, where $H$. cristata is instead present; Kingdon 2015). As summarized in Fig. 10, the first occurrence of $H$. makapanensis is in the late Zanclean of Laetoli (Upper Laetolil Beds). In the Piacenzian, the species is found in the type locality of Makapansgat (members 3-4), in Laetoli (Upper Ndolanya Beds), and in Hadar (Submember SH-2), although with a single specimen recognized so far. Finally, during the Gelasian and Calabrian, H. makapanensis occurs in Omo Shungura (Member G), Gondolin (GD 2 and GD A), and Olduvai Gorge (Bed I). In these two latter sites, the last occurrence of the species is recorded close to the Gelasian-Calabrian transition. In other South African Early Pleistocene sites (Kromdraai A, Swartkrans Member 1, Sterkfontein Member 5), the presence of $H$. cf. makapanensis is here reported.

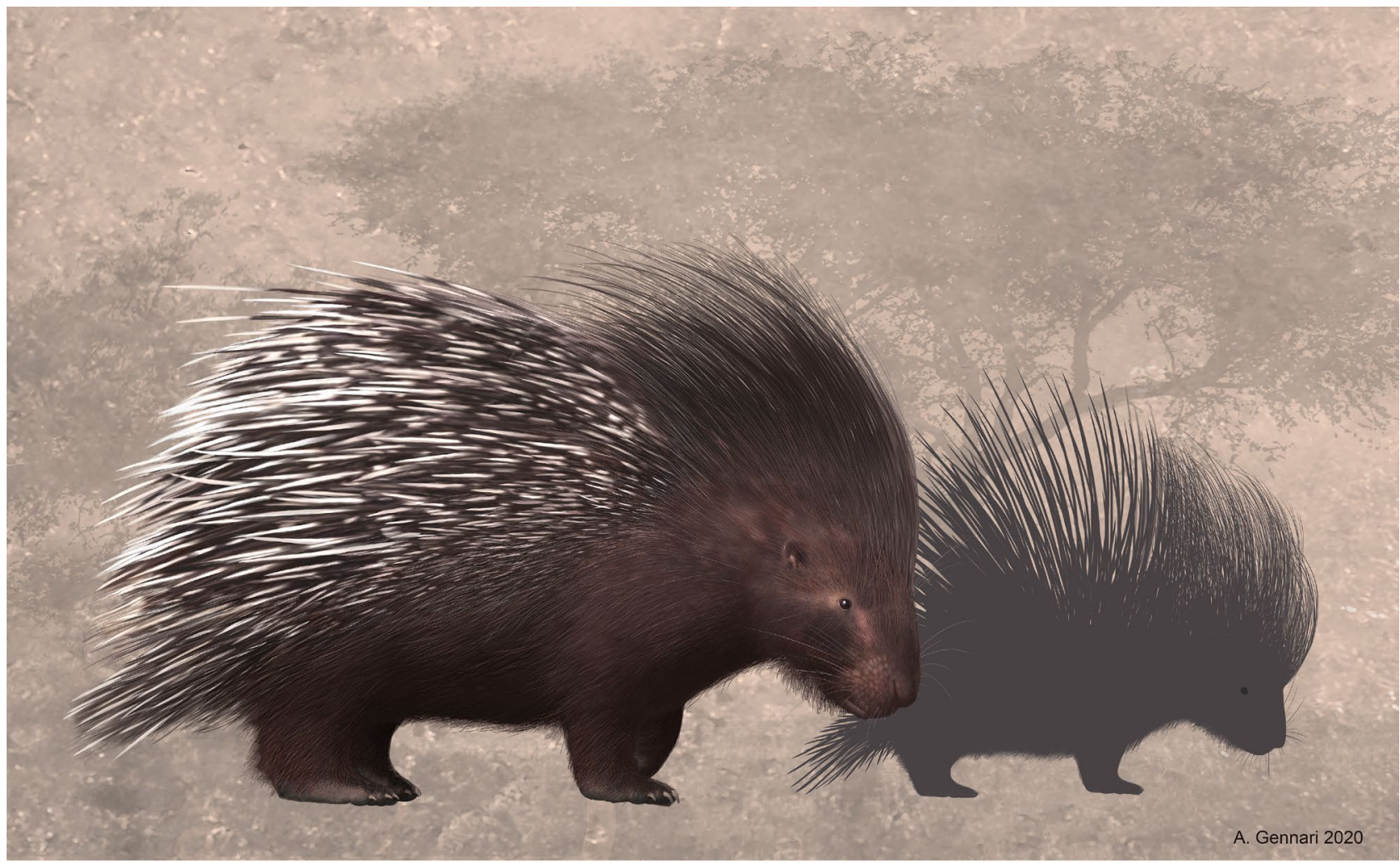

Fig. 11 Life appearance of Hystrix makapanensis (left) compared with extant Hystrix africaeaustralis (right). The estimated average body mass of $H$. makapanensis is about $25.7 \mathrm{~kg}$, compared with about $15 \mathrm{~kg}$ for extant $H$. africaeaustralis. Artwork by Alberto Gennari 
Unfortunately, due to the lack of stratigraphic information, the age of the only specimen from Kenya (i.e., mandible KNM BC432 from Chemeron) cannot be assessed. Among these, the Olduvai sample (including the new mandible LCOG THOR15\#81) undoubtedly represents one of the most interesting for its richness, state of preservation, and abundance of key material to clarify diagnostic aspects of the anatomy of this large-sized porcupine (Fig. 11), which has inhabited Africa for at least two million years.

Supplementary Information The online version contains supplementary material available at https://doi.org/10.1007/s10914-021-09588-z.

Acknowledgements This work is the result of extensive international collaboration, without which we would not have been able to collect so much comparative data on extinct and extant porcupines, especially during the hard times of the Covid-19 pandemic. The following people is sincerely acknowledged: Marion Bamford (University of the Witwatersrand) for bibliographic data on South African porcupines; Pip Brewer (Natural History Museum London) for information and pictures on fossil Hystrix from Olduvai; Brigette Cohen (Florisbad Quaternary Research Station) for fruitful discussions on fossil porcupines from Coopers D; Loïc Costeur (Natural History Museum Basel) for data on extant Hystrix specimens; Terry Harrison (New York University) for making available the Laetoli collection, for the constructive discussion, and the cold beer after working in Dar es Salaam; Thomas Schossleitner (Natural History Museum Berlin) for information on fossil porcupines stored in Berlin. We thank the following people for having granted access to zoological collections: Paolo Agnelli (Museo di Storia Naturale, Università di Firenze), Mauro Bon (Museo di Storia Naturale di Venezia), Fabrizio Cancelli and Giuseppe Manganelli (Museo di Storia Naturale dell'Accademia dei Fisiocritici di Siena), Alberto Camporesi and Daniela Minelli (Collezione di Anatomia Comparata, Università di Bologna), Richard David (University of Pretoria), Adriano De Faveri (ISPRA), Simone Farina (Museo di Storia Naturale, Università di Pisa), Roberta Improta and Maria Rosaria Ghiara (Università degli Studi di Napoli Federico II), Suzanne Jiquel and AnneLise Charruault (Institut des Sciences de 1'Evolution Montpellier), Daniela C. Kalthoff (Natural History Museum Stockholm), Mario Lo Valvo (Laboratorio di Zoologia Applicata, Università di Palermo), Mattia Panzeri (Università dell'Insubria), Roberto Portela-Miguez (Natural History Museum London), Luis Reino (Universitade do Porto), Caterina Senini (Università di Bologna), Sifelani Jirah (Evolutionary Studies Institute, University of the Witwatersrand), Heidi Fourie and Teresa Kearney (Ditsong Museum of Natural History). We thank Fredrick K. Manthi, Job M. Kibii, Rose Nyaboke, and Stephen Maikweki (Nairobi National Museum, National Museums of Kenya) for having granted access to Kenyan collections, for pictures of porcupine specimens, and for their kind support. Heartfelt thanks are due to palaeoartist Alberto Gennari (http://albertogennari68.blogspot.com) for his amazing artworks. We thank all the Italian and Tanzanian participants in the fieldworkshops of the School of Paleoanthropology of the University of Perugia (http://www.paleoantropologia.it) and of the THOR project (http://thorproject.it). The Leakey Camp staff and Maasai Community are equally acknowledged. In particular, we thank Agustino Venance Songita for his excellent work of fossil hunting and Daniel Mainoya for the preparation of LCOG THOR15\#81. We acknowledge the Tanzania Commission for Science and Technology (COSTECH), the Antiquities Division of the Ministry of Natural Resources and Tourism, and the Ngorongoro Conservation Area Authority (NCAA) for research permits and all their support. Comments by Jon Bloch and Natasha Vitek allowed us to significantly improve this article.
Authors' Contributions Conceptualization: Marco Cherin, Beatrice Azzarà \& Lorenzo Fressoia; Data curation: Beatrice Azzarà, Justin Adams, Marco Cherin, Marco Crotti, Christiane Denys, Lorenzo Fressoia, Jackson S. Kimambo, Amandus Kwekason, Sahleselasie Melaku, Emiliano Mori, Bernhard Zipfel; Formal Analysis: Beatrice Azzarà, Marco Cherin \& Lorenzo Fressoia; Funding acquisition: Marco Cherin \& Giorgio Manzi; Investigation: Beatrice Azzarà, Justin Adams, Marco Cherin \& Lorenzo Fressoia; Methodology: Marco Cherin, Beatrice Azzarà \& Lorenzo Fressoia; Project administration: Marco Cherin, Giorgio Manzi \& Fidelis T. Masao; Resources: Justin Adams, Marco Crotti, Christiane Denys, Jackson S. Kimambo, Amandus Kwekason, Sahleselasie Melaku, Emiliano Mori \& Bernhard Zipfel; Software: Dawid A. Iurino \& Sofia Menconero; Supervision: Marco Cherin; Validation: Marco Cherin, Giovanni Boschian \& Giorgio Manzi; Visualization: Beatrice Azzarà, Marco Cherin, Dawid A. Iurino \& Sofia Menconero; Writing - original draft: Beatrice Azzarà, Justin Adams, Marco Cherin, Lorenzo Fressoia \& Emiliano Mori; Writing - review \& editing: Beatrice Azzarà, Marco Cherin, Giovanni Boschian.

Funding This research was funded by the School of Paleoanthropology of the University of Perugia (responsible MC) and by the Italian Ministry of Foreign Affairs and International Cooperation (Italian Archaeological, Anthropological and Ethnological Missions Abroad program; grant numbers: Arc-614, Arc-375, Arc-001868, Arc-001613; responsible GM). JSK was supported by a scholarship from the Italian Ministry of Foreign Affairs and International Cooperation (Study in Italy program; responsible MC).

Availability of Data and Material All data generated or analyzed during this study are included in this published article and its Online Resources.

\section{Declarations}

Ethics Approval This study contains no studies of human participants or animals performed by any of the authors. This article is also not in consideration for or published at any other journal.

Consent to Participate This study contains no human participants.

Consent for Publication No materials or figures have been published elsewhere.

Conflict of Interest The authors declare that they have no known competing financial interests.

\section{References}

Adams J (2006) Taphonomy and paleoecology of the Gondolin Plio-Pleistocene cave site, South Africa. Unpublished Dissertation,Washington University

Adams JW (2012a) Craniodental and postcranial remains of the extinct porcupine Hystrix makapanensis Greenwood, 1958 (Rodentia: Hystricidae) from Gondolin, South Africa. Ann Ditsong Mus Nat Hist 2(7):17

Adams JW (2012b) A revised listing of fossil mammals from the Haasgat cave system ex situ deposits (HGD), South Africa. Palaeontol Electron 15188

Adams JW (2018) Fossil mammals from the Gondolin Dump A ex situ hominin deposits, South Africa. PeerJ 6:e5393

Adams J, Conroy GC (2005) Plio-Pleistocene faunal remains from the Gondolin GD 2 in situ assemblage, North West Province, South Africa. In: Lieberman DJ, Smith RJ, Kelley J (eds) Interpreting 
the Past: Essays on Human, Primate and Mammal Evolution in Honor of David Pilbeam, Brill Academic Publishers, pp 243-261

Adams JW, Herries AI, Kuykendall KL, Conroy GC (2007) Taphonomy of a South African cave: geological and hydrological influences on the GD 1 fossil assemblage at Gondolin, a Plio-Pleistocene paleocave system in the Northwest Province, South Africa. Quat Sci Rev 26:2526-2543

Albert RM, Bamford MK, Stanistreet IG, Stollhofen H, Rivera-Rondón CA, Njau JK, Blumenschine RJ (2018) River-fed wetland palaeovegetation and palaeoecology at the HWK W site, Bed I, Olduvai Gorge. Rev Palaeobot Palynol 259:223-241

Alemseged Z (2003) An integrated approach to taphonomy and faunal change in the Shungura Formation (Ethiopia) and its implication for hominid evolution. J Hum Evol 44:1-28

Álvarez A, Arnal M (2015) First approach to the paleobiology of extinct Prospaniomys (Rodentia, Hystricognathi, Octodontoidea) through head muscle reconstruction and the study of craniomandibular shape variation. J Mammal Evol 22:519-533

Amori G, Contoli L, Nappi A (2008) Mammalia II. Erinaceomorpha, Soricomorpha, Lagomorpha, Rodentia. Collana "Fauna d'Italia". Vol. XLIV. Edizioni Calderini de Il Sole 24 Ore Business Media Srl, Milano

Arambourg C (1959) Vertébrés continenteaux du Miocène supérieur de l'Afrique du Nord. Publications du Service de la Carte Geologique de l'Algerie, Paleontologie 4:101-161

Azzarà B, Boschian G, Brochu CA, Delfino M, Iurino, DA et al (2021) A new cranium of Crocodylus anthropophagus from Olduvai Gorge, Northern Tanzania. Riv Ital Paleontol S 127:275-295

Balter V, Blichert-Toft J, Braga J, Telouk P, Thackeray F, Albarède F (2008) U-Pb dating of fossil enamel from the Swartkrans Pleistocene hominid site, South Africa. EPSL 267:236-246

Barthelmess EL (2006) Hystrix africaeaustralis. Mamm Species 2006:1-7

Bennett CE, Marshall JD, Stanistreet IG (2012) Carbonate horizons, paleosols, and lake flooding cycles: Beds I and II of Olduvai Gorge, Tanzania. J Hum Evol 63:328-341

Brain CK (1981) The Hunters or the Hunted? An Introduction to African Cave Taphonomy. University of Chicago Press, Chicago

Broom R (1938) Further evidence on the structure of the South African Pleistocene anthropoids. Nature 142:897-899

Broom R, Robinson JT (1952) Swartkrans Ape-Man, Paranthropus crassidens. Transvaal Museum Memoir 6, Pretoria

Boisserie J., Guy F, Delagnes A, Hlukso LJ, Bibi F, Beyene Y, Guillemot C (2008) New palaeoanthropological research in the PlioPleistocene Omo group, lower Omo Valley, SNNPR (southern nations, nationalities and people regions), Ethiopia. C R Palevol 7:429-439

Campisano CJ, Feibel CS (2008) Depositional environments and stratigraphic summary of the Pliocene Hadar formation at Hadar, Afar depression, Ethiopia. Geol Soc Am Spec Pap 446:179-201

Cherin M, Iurino DA, Jackson K, Masao FT (2016) New material of hyaenids (Mammalia, Carnivora) from Olduvai Gorge, Tanzania (Early Pleistocene). Boll Soc Paleontol Ital 55:1-9

Collings GE, Cruikshank ARI, Maguire JM, Randall RM (1976) Recent faunal studies at Makapansgat Limeworks, Transvaal, South Africa. Ann S Afr Mus 71:153-165

Corbet NU (1991) Space use and group living in the Cape porcupine (Hystrix africaeaustralis Peters, 1852). Unpublished Dissertation, University of Pretoria

Corbet GB, Jones LA (1965) The specific characters of the crested porcupines, subgenus Hystrix. Proc Zool Soc Lond 144:285-300

Day MH (1976) Hominid postcranial material from Bed I, Olduvai Gorge. In: Isaac $\mathrm{G}$ and McCown ER (eds) Human Origins: Louis Leakey and the East African Evidence, pp 363-374 de Graaff G (1960) A preliminary investigation of the mammalian microfauna in Pleistocene deposits in the Transvaal System. Pal Africana 7:59-118

de la Torre I, Albert RM, Arroyo A, Macphail R, McHenry LJ, Mora $R$ et al (2018) New excavations at the HWK EE site: Archaeology, paleoenvironment and site formation processes during late Oldowan times at Olduvai Gorge, Tanzania. J Hum Evol 120:140-202

de Ruiter DJ (2003) Revised faunal lists for Members 1-3 of Swartkrans, South Africa. Ann Transvaal Mus 40:29-41

de Ruiter DJ, Brophy JK, Lewis PJ, Churchill SE, Berger LR (2008) Faunal assemblage composition and paleoenvironment of Plovers Lake, a Middle Stone Age locality in Gauteng Province, South Africa. J Hum Evol 55:1102-1117

Deino AL (2011) ${ }^{40} \mathrm{Ar} /{ }^{39} \mathrm{Ar}$ dating of Laetoli, Tanzania. In: Harrison $\mathrm{T}$ (ed) Paleontology and Geology of Laetoli: Human Evolution In Context. Springer, Dordrecht, pp 77-97

Deino A, Hill A (2002) ${ }^{40} \mathrm{Ar} /{ }^{39} \mathrm{Ar}$ dating of Chemeron Formation strata encompassing the site of hominid KNM-BC 1, Tugen Hills, Kenya. J Hum Evol 42:141-151

Denys C (1987) Fossil rodents (other than Pedetidae) from Laetoli. In: Leakey MD and Harris JM (eds), Laetoli: A Pliocene Site in Northern Tanzania. Oxford University Press, New York, pp 118-170

Denys C (2011) Rodents. In: Harrison T (ed) Paleontology and Geology of Laetoli: Human Evolution In Context. Springer, Dordrecht, pp $15-53$

Denys C, Sandrock O, Kullmer O, Rozzi FR, Bromage TG, Schrenk F (2011) Note on the presence of Hystrix (Mammalia, Rodentia) in the Malawi Chiwondo Beds (Plio-Pleistocene): taphonomical and palaeoecological implications. Geodiversitas 33:729-738

Edwards TL, Brandon MA, Durand G, Edwards NR, Golledge NR, Holden PB et al (2019) Revisiting Antarctic ice loss due to marine ice-cliff instability. Nature 566:58-64

Ewer RF (1956) The dating of the Australopithecinae: faunal evidence. S Afr Archaeol Bull 11:41-45

Ewer RF (1958) The fossil Suidae of Makapansgat. Proc Zool Soc London 130:329-372

Feibel CS, Brown FH, McDougall I (1989) Stratigraphic context of fossil hominids from the Omo Group deposits: northern Turkana Basin, Kenya and Ethiopia. Am J Phys Anthropol 78:595-622

Ferraz KMPMDB, Bonach K, Verdade LM (2005) Relationship between body mass and body length in capybaras (Hydrochoerus hydrochaeris). Biota Neotrop 5:197-200

Gervais P (1852) Zoologie et paléontologie françaises (animaux vertébrés): ou nouvelles recherches sur les animaux vivants et fossiles de la France (Vol. 1). Harvard University, Cambridge

Gibbon RJ, Pickering TR, Sutton MB, Heaton JL, Kuman K, Clarke $\mathrm{RJ}$ et al (2014) Cosmogenic nuclide burial dating of homininbearing Pleistocene cave deposits at Swartkrans, South Africa. Quat Geochronol 24:10-15

Greenwood M (1955) Fossil Hystricoidea from the Makapan Valley, Transvaal. Palaeont Afr 3:77-85

Greenwood M (1958) Fossil Hystricoidea from the Makapan Valley. Transvaal: Hystrix makapanensis nom. nov. for Hystrix major Greenwood. Ann Mag Nat Hist 13:365

Haile-Selassie Y, Woldegabriel G, White TD, Bernor RL, Degusta D, Renne PR et al (2004) Mio-Pliocene mammals from the Middle Awash, Ethiopia. Geobios 37:536-552

Happold DCD (2013) Mammals of Africa: Volume III: Rodents, Hares and Rabbits. Bloomsbury Publishing, London

Hay R (1976) Geology of the Olduvai Gorge: A Study of Sedimentation in a Semiarid Basin. University of California Press, Berkeley, California 
Herries AI, Adams JW (2013) Clarifying the context, dating and age range of the Gondolin hominins and Paranthropus in South Africa. J Hum Evol 65:676-681

Herries AI, Shaw J (2011) Palaeomagnetic analysis of the Sterkfontein palaeocave deposits: Implications for the age of the hominin fossils and stone tool industries. J Hum Evol 60:523-539

Herries AI, Adams JW, Kuykendall KL, Shaw J (2006) Speleology and magnetobiostratigraphic chronology of the GD 2 locality of the Gondolin hominin-bearing paleocave deposits, North West Province, South Africa. J Hum Evol 51:617-631

Herries AI, Curnoe D, Adams JW (2009) A multi-disciplinary seriation of early Homo and Paranthropus bearing palaeocaves in southern Africa. Quatern Int 202:14-28

Herries AI, Pickering R, Adams JW, Curnoe D, Warr G, Latham AG et al (2013) A multi-disciplinary perspective on the age of Australopithecus in southern Africa. In: The paleobiology of Australopithecus. Springer, Dordrecht, pp 21-40

Hlusko LJ (2007) Earliest evidence for Atherurus and Xenohystrix (Hystricidae, Rodentia) in Africa, from the late Miocene site of Lemudong'o, Kenya. Kirtlandia 56:86-91

Hooijer DA (1958) Fossil rhinoceroses from the Limeworks Cave, Makapansgat. Pal Africana 6:1-13

Johanson DC, Taieb M (1976) Plio-Pleistocene hominid discoveries in Hadar, Ethiopia. Nature 260:293-297

Johanson DC, White TD, Coppens Y (1978) A new species of the genus Australopithecus (Primates: Hominidae) from the Pliocene of eastern Africa. Kirtlandia 28:1-14

Johanson DC, Lovejoy CO, Kimbel WH, White TD, Ward SC, Bush $\mathrm{ME}$, et al (1982) Morphology of the Pliocene partial hominid skeleton (AL 288-1) from the Hadar Formation, Ethiopia. Am J Phys Anthropol 57:403-451.

Jorayev G, Wehr K, Benito-Calvo A, Njau J, de la Torre I (2016) Imaging and photogrammetry models of Olduvai Gorge (Tanzania) by unmanned aerial vehicles: A high-resolution digital database for research and conservation of Early Stone Age sites. J Archaeol Sci 75:40-56

Kimbel WH, Rak Y, Johanson DC (2004) The skull of Australopithecus afarensis. Oxford University Press.

Kingdon J (2015) The Kingdon Field Guide to African Mammals. Bloomsbury Publishing, London

Kuman K (2007) Breathing Life into Fossils: Taphonomic Studies in Honor of C.K. (Bob) Brain. Stone Age Institute Press, Indiana

Kuman K, Clarke RJ (2000) Stratigraphy, artefact industries and hominid associations for Sterkfontein, Member 5. J Hum Evol 38:827-847

Lacruz RS, Brink JS, Hancox J, Skinner AS, Herries A, Schmidt P et al (2002) Palaeontology, geological context and palaeoenvironmental implications of a Middle Pleistocene faunal assemblage from the Gladysvale Cave, South Africa. Pal Africana 38:99-114

Latham AG, Herries A, Quinney P, Sinclair A, Kuykendall K (1999) The Makapansgat australopithecine site from a speleological perspective. Geol Soc Spec Publ 165:61-77

Leakey LSB (1959) A new fossil skull from Olduvai. Nature $184: 491-493$

Leakey LSB (1967) Olduvai Gorge 1951-1961: Fauna and Background. Cambridge University Press, Cambridge

Leakey MD (1971) Olduvai Gorge. Excavations in Beds I and II, 19601963. Cambridge University Press, Cambridge

Leakey LSB, Hopwood AT, Reck H (1951) Olduvai Gorge: A Report on the Evolution of the Hand-axe Culture in Beds I-IV. Cambridge University Press

Leakey LSB, Tobias PV, Napier JR (1964) A new species of the genus Homo from Olduvai Gorge. Nature 202: 7-9

Leakey MD, Harris JM (1987) Laetoli: A Pliocene Site in Northern Tanzania. Oxford, Clarendon
Leakey MD, Hay RL (1979) Pliocene footprints in the Laetolil Beds at Laetoli, northern Tanzania. Nature 278:317-323

Leakey MD, Hay RL, Curtis GH, Drake RE, Jackes MK, White TD (1976) Fossil hominids from the Laetolil Beds. Nature 262:460-466

Lopatin AV, Tesakov AS, Titov VV (2003) Late Miocene-early Pliocene porcupines (Rodentia, Hystricidae) from south European Russia. Russ J Theriol 2:26-32

Maguire JM (1976) A taxonomic and ecological study of the living and fossil Hystricidae with particular reference to southern Africa. Unpublished Dissertation, University of The Witwatersrand

Maguire JM (1978) Southern African fossil porcupines. S Afr J Sci $74: 144$

Manthi FK (2006) The Pliocene micromammalian fauna from Kanapoi, northwestern Kenya, and its contribution to understanding the environment of Australopithecus anamensis. Unpublished Dissertation, University of Cape Town

Masao FT, Ichumbaki EB, Cherin M, Barili A, Boschian G, Iurino DA, et al (2016) New footprints from Laetoli (Tanzania) provide evidence for marked body size variation in early hominins. eLife 5:19568

Masini F, Rook L (1993) Hystrix primigenia (Mammalia Rodentia) from the Late Messinian of the Monticino gypsum Quarry (Faenza, Italy). Boll Soc Paleontol Ital 32:79-87

Menter CG, Kuykendall K., Keyser AW, Conroy GC (1999) First record of hominid teeth from the Plio-Pleistocene site of Gondolin, South Africa. J Hum Evol 37: 299-307

Millien V, Bovy H (2010) When teeth and bones disagree: body mass estimation of a giant extinct rodent. J Mammal 91:11-18

Mori E, Lovari S (2014) Sexual size monomorphism in the crested porcupine (Hystrix cristata). Mamm Biol 79:157-160

Mori E, Ancillotto L, Lovari S, Russo D, Nerva L, Mohamed WF et al (2019) Skull shape and Bergmann's rule in mammals: hints from Old World porcupines. J Zool 308, 47-55

Partridge TC (1979) Re-appraisal of lithostratigraphy of Makapansgat Limeworks hominid site. Nature 279:484-488

Pickering TR (1999) Taphonomic interpretations of the Sterkfontein early hominid site (Gauteng, South Africa) reconsidered in light of recent evidence. Unpublished Dissertation, University of Wisconsin

Pickering TR, Egeland CP, Domínguez-Rodrigo M, Brain CK, Schnell AG (2008) Testing the "shift in the balance of power" hypothesis at Swartkrans, South Africa: Hominid cave use and subsistence behavior in the Early Pleistocene. J Anthropol Archaeol 27:30-45

Pickering TR, Heaton JL, Clarke RJ, Stratford D (2019) Hominin vertebrae and upper limb bone fossils from Sterkfontein Caves, South Africa (1998-2003 excavations). Am J Phys Anthropol 168:459-480

Pickford M, Wanas H, Mein P, Soliman H (2008) Humid conditions in the western desert of Egypt during the Vallesian (Late Miocene). Bull Tethys Geol Soc 3:63-79

Reed KE (1996) The paleoecology of Makapansgat and other African Plio-Pleistocene hominid localities. Unpublished Dissertation, State University of New York

Rovie-Ryan JJ, Khan FAA, Zainuddin ZZ, Ahmad AH, Gani M, Julaihi AM, Saaban S (2017) Molecular phylogeny of the Old World porcupines (family Hystricidae) using mitochondrial cytochrome b gene. JSSM 12:1-11

Sabatier M (1978) Les rongeurs des sites à hominidés de Hadar et Melka-Kenture (Ethiopie). Unpublished Dissertation, Université des Sciences et Techniques de Languedoc

Sen S (2001) Early Pliocene porcupine (Mammalia, Rodentia) from Perpignan, France: A new systematic study. Geodiversitas 23:303-312 
Sen S, Purabrishemi Z (2010) First porcupine fossils (Mammalia, Rodentia) from the late Miocene of NW Iran, with notes on late Miocene-Pliocene dispersal of porcupines. Palaeont $\mathrm{Z}$ 84:239-248

Smithers RHN (1983) The mammals of the southern African subregion. University of Pretoria Press

Stanistreet IG, McHenry LJ, Stollhofen H, de la Torre I (2018) Bed II Sequence Stratigraphic context of EF-HR and HWK EE archaeological sites, and the Oldowan/Acheulean succession at Olduvai Gorge, Tanzania. J Hum Evol 120:19-31

Stanistreet IG, Stollhofen H, Deino AL, McHenry LJ, Toth NP, Schick KA, Njau JK (2020) New Olduvai Basin stratigraphy and stratigraphic concepts revealed by OGCP cores into the Palaeolake Olduvai depocentre, Tanzania. Palaeogeogr Palaeoclimatol Palaeoecol 554:109751

Tobias PV (1991) Olduvai Gorge: The Skulls, Endocasts and Teeth of Homo habilis. Cambridge University Press, Cambridge

Toerien MJ (1952) The fossil hyaenas of the Makapansgat Valley. S Afr J Sci 48:293-300

Trucchi E, Sbordoni V (2009) Unveiling an ancient biological invasion: molecular analysis of an old European alien, the crested porcupine (Hystrix cristata). BMC Evol Biol 9:109

Trucchi E, Facon B, Gratton P, Mori E, Stenseth NC, Jentoft S (2016) Long live the alien: is high genetic diversity a pivotal aspect of crested porcupine (Hystrix cristata) long-lasting and successful invasion? Mol Ecol 25:3527-3539

Uribelarrea D, Perea DM, Díez-Martín F, Baquedano E, Mabulla A, Barba R et al (2019) A geoarchaeological reassessment of the co-occurrence of the oldest Acheulean and Oldowan in a fluvial ecotone from lower middle Bed II (1.7 ma) at Olduvai Gorge (Tanzania). Quarter Int 526:39-48 van Weers DJ (2003) The porcupine Hystrix (Acanthion) brachyura punungensis subsp. Scripta Geologica 126:217-225

van Weers DJ (2005) A taxonomic revision of the Pleistocene Hystrix (Hystricidae, Rodentia) from Eurasia with notes on the evolution of the family. Contrib Zool 74:301-312

van Weers DJ, Rook L (2003) Turolian and Ruscinian porcupines (genus Hystrix, Rodentia) from Europe, Asia and N. Africa. Palaeont $Z$ 77:95-113

Vignaud P, Duringer P, Mackaye HT, Likius A, Blondel C, Boisserie J $R$ et al (2002) Geology and palaeontology of the Upper Miocene Toros-Menalla hominid locality, Chad. Nature 418:152-155

Watson V (1993) Glimpses from Gondolin: A faunal analysis of a fossil site near Broederstroom, Transvaal, South Africa. Pal Africana 30: $35-42$

Wells LH, Cooke HBS (1956) Fossil Bovidae from the Limeworks Quarry, Makapansgat, Potgietersrus. Palaeont A fr 4:12-15

Wesselman HB, Black MT, Asnake M (2009) Small mammals. In: Haile-Selassie Y and WoldeGabriel G (eds) Ardipithecus kadabba: Late Miocene Evidence from the Middle Awash, Ethiopia. Berkeley, University of California Press, pp. 105-134

Winkler A (2003) Rodents and lagomorphs from the Miocene and Pliocene of Lothagam, northern Kenya. In: Leakey M and Harris J (eds) Lothagam: The Dawn of Humanity in Eastern Africa. New York, Columbia University Press, pp 169-198

Winkler A, Denys C, Avery DM (2010) Fossil rodents of Africa. In: Werdelin L and Sanders WJ (eds) Cenozoic Mammals of Africa. California Press, Oakland, pp 263-304

Wood B (2011) Did early Homo migrate "out of" or "in to" Africa? PNAS 108:10375-10376

\section{Authors and Affiliations}

\section{Beatrice Azzarà ${ }^{1} \cdot$ Marco Cherin ${ }^{1}$ (D) Justin Adams ${ }^{2,3,4}$. Giovanni Boschian ${ }^{4,5} \cdot$ Marco Crotti $^{6}$. Christiane Denys ${ }^{7}$. Lorenzo Fressoia $^{1}$ - Jackson S. Kimambo ${ }^{1,8}$. Amandus Kwekason ${ }^{9}$. Dawid A. lurino ${ }^{10}$. Giorgio Manzi ${ }^{11}$. Fidelis T. Masao ${ }^{12}$. Sahleselasie Melaku ${ }^{13,14}$. Sofia Menconero ${ }^{15} \cdot$ Emiliano Mori $^{16} \cdot$ Bernhard Zipfel $^{8}$}

1 Dipartimento di Fisica e Geologia, Università degli Studi di Perugia, Via A. Pascoli, Perugia 06123, Italy

2 Department of Anatomy and Developmental Biology, Biomedicine Discovery Institute, Monash University, Melbourne 3800, Australia

3 Museums Victoria, Melbourne 3053, Australia

4 Palaeo-Research Institute, University of Johannesburg, Auckland Park, Johannesburg 2006, South Africa

5 Dipartimento di Biologia, Università di Pisa, Via Derna, Pisa 56126, Italy

6 Institute of Biodiversity, Animal Health \& Comparative Medicine, College of Medical, Veterinary \& Life Sciences, University of Glasgow, Glasgow G12 8QQ, UK

7 Institut de Systématique, Evolution, Biodiversité (ISYEB), Muséum national d'Histoire naturelle, CNRS, Sorbonne Université, EPHE, Université Des Antilles, CP 51, 57 rue Cuvier, 75005 Paris, France

8 Evolutionary Studies Institute, University of the Witwatersrand, Private Bag 3, Wits 2050, Johannesburg, South Africa
9 National Museum of Tanzania, Shaban Robert Street, P.O. Box 511, Dar es Salaam, Tanzania

10 PaleoFactory, Dipartimento di Scienze della Terra, Sapienza Università di Roma, Piazzale A. Moro 5, Roma 00185, Italy

11 Dipartimento di Biologia Ambientale, Sapienza Università di Roma, Piazzale A. Moro 5, Roma 00185, Italy

12 Department of Archaeology \& Heritage, College of Humanities, University of Dar Es Salaam, P.O. Box 35050, Dar es Salaam, Tanzania

13 Authority for Research and Conservation of Cultural Heritage (ARCCH), National Museum of Ethiopia, Addis Ababa, Ethiopia

14 Paleoanthropology and Paleoenvironment Program, Addis Ababa University, Addis Ababa, Ethiopia

15 Dipartimento di Storia, Disegno e Restauro dell'Architettura, Sapienza Università di Roma, Piazza Borghese 9, Roma 00186, Italy

16 Consiglio Nazionale delle Ricerche, Istituto di Ricerca sugli Ecosistemi Terrestri, Via Madonna del Piano 10, Sesto Fiorentino (Florence) 50019, Italy 